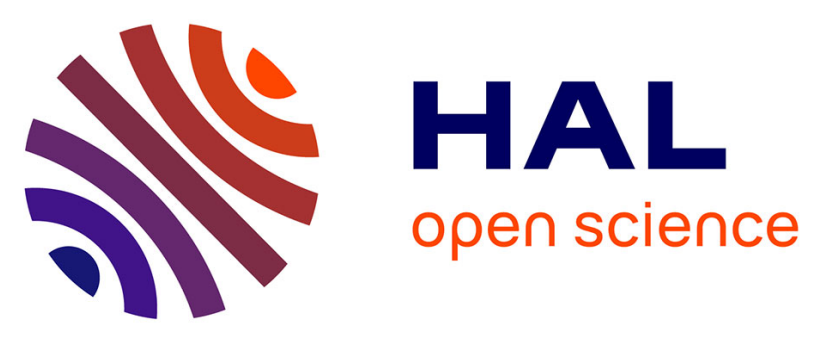

\title{
Coexistence and Impact of Limb Muscle and Diaphragm Weakness at Time of Liberation from Mechanical Ventilation in Medical Intensive Care Unit Patients
}

Martin Dres, Bruno-Pierre Dubé, Julien Mayaux, Julie Delemazure, Danielle Reuter, Laurent Brochard, Thomas Similowski, Alexandre Demoule

\section{To cite this version:}

Martin Dres, Bruno-Pierre Dubé, Julien Mayaux, Julie Delemazure, Danielle Reuter, et al.. Coexistence and Impact of Limb Muscle and Diaphragm Weakness at Time of Liberation from Mechanical Ventilation in Medical Intensive Care Unit Patients. American Journal of Respiratory and Critical Care Medicine, 2016, 195 (1), pp.57-66. 10.1164/rccm.201602-0367OC . hal-01458947

\section{HAL Id: hal-01458947 https: / hal.sorbonne-universite.fr/hal-01458947}

Submitted on 7 Feb 2017

HAL is a multi-disciplinary open access archive for the deposit and dissemination of scientific research documents, whether they are published or not. The documents may come from teaching and research institutions in France or abroad, or from public or private research centers.
L'archive ouverte pluridisciplinaire HAL, est destinée au dépôt et à la diffusion de documents scientifiques de niveau recherche, publiés ou non, émanant des établissements d'enseignement et de recherche français ou étrangers, des laboratoires publics ou privés. 


\section{Coexistence and impact of limb muscle and diaphragm weakness at time of liberation from mechanical ventilation in medical ICU patients}

Martin Dres ${ }^{1,2}, \mathrm{MD}^{*}$, Bruno-Pierre Dubé ${ }^{1,3}, \mathrm{MD}^{*}$, Julien Mayaux ${ }^{2}, \mathrm{MD}, \mathrm{MD}$, Julie Delemazure $^{2}, \mathrm{MD}$, Danielle Reuter ${ }^{2}, \mathrm{MD}$, Laurent Brochard ${ }^{4,5}, \mathrm{MD}, \mathrm{PhD}$, Thomas Similowski ${ }^{1,2}, \mathrm{MD}, \mathrm{PhD} ;$ Alexandre Demoule ${ }^{1,2}, \mathrm{MD}, \mathrm{PhD}$

${ }^{*}$ The first two authors contributed equally to this work

${ }^{1}$ Sorbonne Universités, UPMC Univ Paris 06, INSERM, UMRS1158

Neurophysiologie respiratoire expérimentale et clinique, Paris, France

${ }^{2}$ AP-HP, Groupe Hospitalier Pitié-Salpêtrière Charles Foix, Service de Pneumologie et Réanimation Médicale (Département "R3S"), F-75013, Paris, France

${ }^{3}$ Département de médecine, service de pneumologie, hôpital Hôtel-Dieu du Centre

Hospitalier de l’Université de Montréal (CHUM), Montréal, Québec, Canada

${ }^{4}$ Keenan Research Centre for Biomedical Science of St. Michael's Hospital

${ }^{5}$ Interdepartmental Division of Critical Care Medicine, University of Toronto

\section{Correspondence:}

Dr Martin Dres

Service de Pneumologie et Réanimation Médicale

Groupe Hospitalier Pitié-Salpêtrière

47-83 boulevard de 1'Hôpital

75651 Paris Cedex 13, France

Phone: 331421677 61; Fax: 33170247282

E-mail: martin.dres@aphp.fr 


\section{Authors' contributions:}

MD and AD designed the study. MD coordinated the study. MD, BPD, JM, DR and JD were responsible for patient screening, enrolment and follow-up. MD, BPD, LB, TS and $\mathrm{AD}$ analyzed the data. MD, BPD, LB, TS and $\mathrm{AD}$ wrote the manuscript. All authors had full access to all of the study data, contributed to drafting the manuscript or critically revised it for important intellectual content, approved the final version of the manuscript, and take responsibility for the integrity of the data and the accuracy of the data analysis.

Funding: M.D. was supported by The French Intensive Care Society (SRLF bourse de mobilité 2015); The 2015 Short Term Fellowship program of the European Respiratory Society; The 2015 Bernhard Dräger Award for advanced treatment of ARF of the European Society of Intensive Care Medicine; The Assistance Publique Hôpitaux de Paris; The Fondation pour la Recherche Médicale (FDM 20150734498) and by Mitacs Globalink Sorbonne Universités. The clinical research of "Département R3S" is supported by the program "investissement d'avenir ANR-10-AIHU 06" of the French Government.

Running head: Diaphragm dysfunction and weaning from mechanical ventilation

Descriptor number: 4.13 Ventilation: Non-Invasive/Long-Term/Weaning.

Word count: 2997 
This article has an online data supplement, which is accessible from this issue's online table of contents.

Conflict of interest: Alexandre Demoule has signed research contracts with Covidien, Maquet and Philips; he has also received personal fees from Covidien. Martin Dres received personal fees from Pulsion Medical System and AstraZeneca. Laurent Brochard has research contracts with Covidien (PAV), Maquet (NAVA), Philips (equipment for sleep), Fisher Paykel (high flow therapy). The others authors have no conflict of interest relevant to this study.

\section{At a glance commentary}

Scientific Knowledge on the Subject: Critically ill patients can develop intensive care unit (ICU) acquired weakness and ICU acquired diaphragm dysfunction. Both have been associated with poor outcome and prolonged weaning from mechanical ventilation. Whether they are two aspects of the same entity or whether they have a different prevalence and prognostic impact remains unclear. Their respective prevalence and coexistence, risks factors and outcome at time of liberation from mechanical ventilation are not known.

What This Study Adds to the Field: At the time of liberation from mechanical ventilation, in a non-selected population, diaphragm dysfunction is twice more frequent as limb muscle weakness. Diaphragm dysfunction is significantly associated with subsequent weaning failure and mortality. 


\section{Abstract (259 words)}

Background. Intensive care unit (ICU) and mechanical ventilation (MV) acquired limb muscle and diaphragm dysfunction may both be associated with longer length of stay and worse outcome. Whether they are two aspects of the same entity or whether they have a different prevalence and prognostic impact remains unclear. This study was designed to quantify the prevalence and coexistence of these two forms of ICUacquired weakness and their impact on outcome.

Methods. In patients undergoing a first spontaneous breathing trial (SBT) after at least $24 \mathrm{~h}$ of MV, diaphragm dysfunction was evaluated using twitch tracheal pressure in response to bilateral anterior magnetic phrenic nerve stimulation (a pressure $<11$ $\mathrm{cmH}_{2} \mathrm{O}$ defined dysfunction) and ultrasonography (thickening fraction (TFdi) and excursion). Limb muscle weakness was defined as a Medical Research Council (MRC) score $<48$.

Results. 76 patients were assessed at their first SBT: $63 \%$ had diaphragm dysfunction, $34 \%$ had limb muscle weakness and $21 \%$ had both. There was a significant but weak correlation between MRC score and twitch pressure $(\mathrm{Rho}=0.26, \mathrm{p}=0.03)$ and TFdi $(\mathrm{Rho}=0.28, \mathrm{p}=0.01)$, respectively. Low twitch pressure (OR 0.60, 95\% CI $0.45-0.79$, $\mathrm{p}<0.001$ ) and TFdi (OR 0.84, 95\%CI 0.76-0.92, $\mathrm{p}<0.001$ ) were independently associated with weaning failure, but the MRC score was not. Diaphragm dysfunction was associated with higher ICU and hospital mortality, and limb muscle weakness was associated with longer duration of MV and hospital stay. 
Conclusions. Diaphragm dysfunction is twice as frequent as limb muscle weakness and has a direct negative impact on weaning outcome. The two types of muscle weakness have only limited overlap.

Keywords: diaphragm dysfunction, ICU acquired weakness, weaning from mechanical ventilation 


\section{Introduction}

It is well established that a substantial proportion of intensive care unit (ICU) patients develop limb muscle weakness, also called ICU-acquired weakness (ICU-AW) $(1,2)$. In turn, ICU-AW is associated with increased duration of mechanical ventilation (MV) and ICU stay (3-7). More recently, it has been shown that mechanically ventilated ICU patients may also experience acquired diaphragm dysfunction $(8,9)$ and atrophy (10), which may cause difficult weaning and increased duration of mechanical ventilation (11-13). Although ICU-acquired limb muscle and diaphragm weaknesses are increasingly described, data regarding their interrelationship and their respective risk factors and prognostic impact are scarce and they have only be investigated in very selected populations $(3,4,13)$. To some extent, ICU-AW and diaphragm dysfunction share similar mechanisms and could be two aspects of the same disease in mechanically ventilated patients submitted to bed rest and general muscle disuse $(8,9$, 14). However, in contrast with limb muscles, the diaphragm contracts phasically and continuously throughout the subject's lifetime. It is currently unknown whether mechanical ventilation has a similar impact on diaphragm and limb muscle strength.

The aim of the present study was to assess whether diaphragm dysfunction and ICU-AW are or not two distinct entities with their own specific prevalence and risk factors. In this purpose, we enrolled a non-selected population of medical ICU patients on the day of their first spontaneous breathing trial (SBT). Diaphragm function was assessed by both phrenic nerve stimulation and ultrasound, and limb muscle strength was assessed by a validated clinical tool. 
The primary objective of the study was to quantify the respective prevalence of ICU-AW and diaphragm dysfunction. We also sought to determine the respective impact of ICU-AW and diaphragm dysfunction on weaning success and their association with clinical outcome.

Some of the results of this study have been previously reported in abstract form (15). 


\section{Methods}

Detailed methods are provided in the online supplement. The study was conducted over an 8-month period (December 1, 2014 to July 31st, 2015) in a medical ICU. The study was approved by the Comité de Protection des Personnes Ile-de-France VI (ID RCB: 2014-A00715-42). Informed consent was obtained from all patients or their relatives.

\section{Patients}

Patients intubated and ventilated for at least $24 \mathrm{~h}$ were eligible for inclusion in the study when they met the predefined readiness-to-wean criteria on daily screening (see online supplement) and were therefore deemed ready to undergo a first 30-minutes SBT (16). Exclusion criteria were related to factors possibly interfering with tracheal pressure measurements in response to phrenic nerve stimulation (see online supplement), tracheostomy and the impossibility to assess muscular strength in a limb because of immobilization or inability to follow simple orders.

\section{Diaphragm strength}

\section{Phrenic nerve stimulation}

Diaphragm strength was assessed in terms of the changes in endotracheal tube pressure induced by bilateral phrenic nerve stimulation during airway occlusion (Ptr,stim), as described elsewhere $(17,18)$ (see online supplement). Stimulations were delivered at the maximum intensity allowed by the stimulator $(100 \%)$ known to result in supramaximal diaphragm contraction in most patients $(8,18-21)$.

Diaphragm ultrasound measurements 
Ultrasound assessment of the diaphragm was performed using a 4-12 $\mathrm{MHz}$ linear array transducer (Sparq ultrasound system, Phillips, Philips Healthcare, MA, USA), using techniques described elsewhere $(22,23)$. Measurements were performed while patients were mechanically ventilated with a standardized pressure-support level targeting a tidal volume of $6-8 \mathrm{ml} / \mathrm{kg}$ of ideal body weight. PEEP was not modified during the measurements. In our unit, PEEP is routinely set at around $5 \mathrm{cmH}_{2} \mathrm{O}$. Diaphragm thickness was measured at end-expiration $\left(\mathrm{T}_{\mathrm{DE}}\right)$ and end-inspiration $\left(\mathrm{T}_{\mathrm{DI}}\right)$ and thickening fraction (TFdi) was calculated offline as $\left(\mathrm{T}_{\mathrm{DI}}-\mathrm{T}_{\mathrm{DE}}\right) / \mathrm{T}_{\mathrm{DE}}$. The maximal excursion of the diaphragm was also measured. Ultrasound measurements were performed by one of the authors (either B-P.D. or M.D.) on at least three separate breaths, and the mean of the three measurements was reported.

\section{Limb muscle strength}

Limb muscle strength was assessed by the Medical Research Council (MRC) score in patients screened for awakening and understanding (see details in the online supplement). MRC scoring was performed jointly by the ICU physiotherapist and one of the investigators (B-P D or MD).

\section{Definitions}

Ptr,stim was used to identify two groups of patients based on the $11 \mathrm{~cm} \mathrm{H}_{2} \mathrm{O}$ cutoff already described $(8,24)$. Patients with a Ptr,stim $<11 \mathrm{cmH}_{2} \mathrm{O}$ were considered to have diaphragm dysfunction. MRC score was used to identify two groups of patients based on the cut-off of 48/60 (14). Patients with an MRC score $<48$ were considered to have ICU-AW.

\section{Clinical data collection}


Demographic data, comorbidities, severity scores, organ dysfunction-related variables, physiological data, blood gas data, medication exposure, duration of MV, ICU and hospital stay and ICU and hospital mortality were prospectively recorded.

\section{Study design}

The SBT was performed after completion of diaphragm and limb muscle assessment. Patients were connected to the ventilator (pressure support level $7 \mathrm{cmH}_{2} \mathrm{O}$, zero end-expiratory pressure) for a 30 minute-period. SBT was considered to have failed when criteria of clinical intolerance were present (see online supplement) (16). Otherwise, the SBT was considered to be successful and patients were extubated according to the decision of the attending physician. Patients who did not meet the predefined clinical intolerance criteria but who were not extubated after completion of the SBT were considered to be weaning failures. Successful weaning was defined as sustained spontaneous breathing without any form of ventilatory support $48 \mathrm{~h}$ after extubation. Weaning failure was defined as patients failing the SBT, requiring reintubation or any form of ventilatory support (including noninvasive ventilation for post-extubation acute respiratory failure, but not prophylactic noninvasive ventilation) during the $48 \mathrm{~h}$ following extubation. In addition, simple, difficult and prolonged weaning were defined according to the international weaning conference (16).

\section{Statistical analysis}

Continuous variables are expressed as median (interquartile range) or mean (standard deviation) and categorical variables are expressed as absolute and relative frequency. Continuous variables were compared with Student t test or Mann-Whitney $\mathrm{U}$ test depending on distribution and categorical variables were compared with Chi- 
square test or Fisher's exact test depending on sample size. The prevalence of each category of the weaning classification (simple, difficult and prolonged weaning) in patients with diaphragm dysfunction and ICU-AW was compared by a Chi-square test. The Spearman correlation was used to test the relationship between MRC score and Ptr,stim and TFdi, respectively.

Multiple regression models were used to identify the effect of exposure pre-SBT variables on the incidence of diaphragm dysfunction, ICU-AW and weaning failure. Finally, the associations of diaphragm dysfunction and ICU-AW on inclusion with duration of MV, length of ICU and hospital stay and mortality were also assessed.

For all final comparisons, a p-value less than or equal to 0.05 was considered statistically significant. Statistical analyses were performed with SPSS, v.21 (IBM, Chicago, Illinois, USA). 


\section{Results}

\section{Study population}

During the study period, 330 patients were admitted, 184 patients were ventilated for at least $24 \mathrm{~h}$ and 76 patients were consecutively enrolled in the study (Figure 1). Patient characteristics on inclusion are detailed in Table 1. Patients had received MV for a median of 4 (2-6) days at the time of inclusion. MRC score could be obtained in all patients. At inclusion, all the patients were ventilated with a mean level of pressure support of $10 \pm 2 \mathrm{cmH}_{2} \mathrm{O}$ and a mean level of PEEP of $6 \pm 1 \mathrm{cmH}_{2} \mathrm{O}$.

\section{Diaphragm and limb muscle weakness}

At the time of their first SBT, forty-eight patients $(63 \%)$ had diaphragm dysfunction, 26 (34\%) had ICU-AW and 16 (21\%) had both (Figure 1). Table 2 displays the patients' clinical characteristics according to the presence of diaphragm dysfunction or ICU-AW. Ptr,stim was similar in patients with and without ICU-AW (9.3 \pm 6.6 vs. $10.5 \pm 6.0 \mathrm{cmH}_{2} \mathrm{O}$, respectively) and MRC score was similar in patients with and without diaphragm dysfunction $(47 \pm 13$ vs. $50 \pm 11$ respectively). There was a significant but very weak correlation between MRC score and Ptr,stim $(\mathrm{Rho}=0.26$, $\mathrm{p}=0.03)$ and between MRC score and TFdi $(\mathrm{Rho}=0.28, \mathrm{p}=0.01)$ (Figure $2 \mathrm{~A}$ and $2 \mathrm{~B})$.

Pre-SBT factors associated with diaphragm dysfunction were age and duration of MV prior to inclusion, whereas ICU admission for coma was inversely associated with diaphragm dysfunction (Table 2). Multivariate analysis showed that admission for coma (OR 0.15, 95\% CI 0.05-0.44, p=0.001) was inversely associated with diaphragm dysfunction (Table E1). Pre-SBT factors associated with ICU-AW were cirrhosis, duration of MV prior to inclusion, propofol exposure and SOFA score at inclusion 
(Table 2). Multivariate analysis showed that longer duration of MV prior to inclusion (OR 1.25, 95\% CI 1.05-1.48), $\mathrm{p}=0.01)$ and cirrhosis (OR 8.20, 95\% CI 1.82-37.00, $\mathrm{p}=0.006$ ) were independently associated with ICU-AW (Table E2).

\section{Weaning outcome}

Thirty-three $(43 \%)$ of the 76 patients presented weaning failure. In the weaning failure group, 26 patients were not extubated at the end of the SBT, whereas the endotracheal tube was removed but ventilatory support had to be resumed within $48 \mathrm{~h}$ for 7 patients. Compared to patients with successful weaning, patients with weaning failure had significantly lower MRC score, lower Ptr,stim, lower TFdi and lower diaphragm excursion (Table 3). In addition, patients in the failure group were older, had received MV for a longer duration prior to inclusion and had a higher $\mathrm{PaCO}_{2}$. Diaphragm dysfunction was more frequent in patients with prolonged and difficult weaning than simple weaning, whereas the prevalence of ICU-AW was similar in the three categories of the weaning classification (Figure 3).

In the three logistic regression models, each including either Ptr,stim, TFdi or excursion as markers of diaphragm function, Ptr,stim (OR 0.60, 95\%CI 0.45-0.79, $\mathrm{p}<0.001$ ), TFdi (OR 0.84, 95\%CI 0.76-0.92, p<0.001) and EXdi (OR 0.15, 95\%CI $0.02-0.94, p=0.04)$ were independently associated with weaning failure (Figure 4 and Tables E3/E4/E5 in the online supplement). In the model including the MRC score, the MRC score was not independently associated with weaning failure (OR 0.96, 95\%CI 0.91-1.02, p=0.20) (Table E6).

\section{Clinical outcome}


Table 4 displays the clinical outcomes of the patients according to the presence of diaphragm dysfunction and ICU-AW on inclusion. Diaphragm dysfunction was associated with difficult weaning, prolonged weaning, prolonged total duration of MV and ICU length of stay and higher ICU and hospital mortality. ICU-AW was associated with longer total duration of MV and hospital length of stay. 


\section{Discussion}

In a non-selected population of mechanically ventilated patients deemed ready to perform a SBT, we found that 1) the prevalence of diaphragm dysfunction was twofold higher than the prevalence of ICU-AW, with only a small overlap between diaphragm dysfunction and ICU-AW and that 2) diaphragm dysfunction but not ICU-AW influenced the success of weaning.

\section{Prevalence and correlation}

This study is the first to report that the prevalence of diaphragm dysfunction at time of liberation from MV was almost twofold higher than the prevalence of ICUAW. A recent study reported a prevalence of diaphragm dysfunction as high as $80 \%$ in patients with ICU-AW entering the weaning process (13). Interestingly, we found a similar proportion of diaphragm dysfunction in our patients with ICU-AW (16/26, $62 \%$ ). The overall prevalence of diaphragm dysfunction observed in the present study was similar to that already described at the time of ICU admission (8). Ventilatorinduced diaphragm dysfunction has been described in specific settings such as brain dead donors (25) and small cohorts of ICU patients $(9,26)$. Several factors, such as sepsis that may be present at ICU admission and responsible for initial diaphragm weakness, might improve with time, while other factors such as ventilator-induced diaphragm dysfunction, may subsequently come into play. However, the respective contributions of mechanical ventilation and diaphragm dysfunction present on admission on the diaphragm dysfunction observed at time of weaning from mechanical ventilation cannot be determined from the results of this study. 
The correlation between diaphragm dysfunction and ICU-AW was weak and the overlap was small. Previous studies have reported a preferential involvement of the diaphragm compared to limb muscles in patients with sepsis (27) or in mice with pneumonia (28). Ventilator-induced muscle dysfunction seems to be specific to respiratory muscles, at least the diaphragm, compared to pectoralis major for example (25). Although diaphragm and limb muscles are both skeletal muscles and share similar cellular pathway $(6,29)$, they appear to differ considerably in terms of their vulnerability to mechanical ventilation and bed rest (30). As this was not a mechanistic study, we can only speculate on the pathophysiological significance of our findings. However, it is essential to determine whether diaphragm dysfunction and ICU-AW are two distinct entities in order to address their possible mechanisms. Immobilization is the most common of the numerous factors that may induce muscle weakness (31). While the spontaneous activity of limb muscles may often be dramatically decreased (during sleep, for example), the diaphragm is characterized by a continuous contractile activity throughout the subject's lifetime, which could explain why the diaphragm is more susceptible to even brief periods of inactivity. This hypothesis is only speculative, but our overall findings suggest that ICU-AW and diaphragm dysfunction are two distinct syndromes probably associated with different pathophysiological pathways.

\section{Impact of diaphragm dysfunction and ICU-AW on weaning failure}

Diaphragm dysfunction was significantly associated with subsequent difficult and prolonged weaning, but ICU-AW was not, confirming the results of previous studies assessing diaphragm dysfunction with phrenic nerve stimulation or ultrasound 
(11-13). As also reported by Kim et al. (11), we found that the maximum excursion of the diaphragm was significantly different according to the outcome of the SBT. Moreover, we also report, for the first time, that TFdi was an independent variable of weaning failure in addition to Ptr,stim. Although ultrasound measurements were performed under pressure support, it was interesting to observe a marked difference in TFdi $(21 \pm 9 \%$ vs. $40 \pm 11 \%)$ between patients with or without diaphragm dysfunction under a similar level of pressure support ventilation $\left(10 \pm 2\right.$ vs. $\left.10 \pm 2 \mathrm{cmH}_{2} \mathrm{O}\right)$. This finding suggests that, despite the same level of support, there was a much lower contribution of the diaphragm in patients with diaphragm dysfunction than in patients without diaphragm dysfunction, as reflected by lower tidal volumes in patients with diaphragm dysfunction.

Although some patients with diaphragm dysfunction can be easily extubated, diaphragm dysfunction was present in almost all patients with weaning failure. In contrast, ICU-AW was not associated with weaning failure, but with a longer duration of MV. These findings could be explained by the small number of cases of ICU-AW diagnosed in our population. However, it is noteworthy that our patients were assessed after a relatively short period of MV compared to other studies focusing on ICU-AW that selected patients who had been ventilated for at least 7 days $(3,4,32)$. Mechanical ventilation is most often associated with bed rest, which may lead to peripheral muscle inactivity and therefore ICU-AW. Whether prolonged duration of MV, by promoting bed rest, leads to ICU-AW (33) or whether ICU-AW induces prolonged duration of MV remains unclear.

\section{Strengths and weakness}


A major strength of our study is the inclusion of unselected mechanically ventilated ICU patients, we did not restrict inclusion to patients with severe ICU-AW or prolonged MV. Our cohort is therefore more likely to reflect the patients encountered in routine ICU practice. Another strength of our study is that we measured diaphragm function by both magnetic stimulation of the phrenic nerve, which constitutes the gold standard but which is a fairly difficult technique, and ultrasound, which is easier to use in everyday practice.

Several limitations must be acknowledged. First, by using phrenic nerve stimulation as the reference technique to define diaphragm dysfunction $(8,13,18)$, we excluded some eligible patients, in whom this technique was contraindicated. The cutoff of $11 \mathrm{cmH}_{2} \mathrm{O}$ of Ptr,stim to define diaphragm dysfunction has been recommended in ICU patients $(17,24)$ and validated in this population by a previous study from our group (8). As the supramaximal nature of phrenic nerve stimulation in terms of diaphragm contraction was not specifically confirmed, we therefore cannot absolutely rule out that incomplete recruitment of phrenic nerve fibers may have contributed to low twitch pressure in some cases. However, phrenic nerve stimulation was delivered at the maximum available intensity $(100 \%$ of the output of paired $2.5 \mathrm{~T}$ biphasic stimulators), an intensity known to result in supramaximal stimulation in most patients $(8,18-21)$.

Second, we defined weaning failure in the presence of clinical intolerance or by the need for any ventilator support during the 48 hours after extubation. However, among the 43 successful patients, only 1 was reintubated between 48 hours and day 7 after extubation. This patient had a Ptr,stim value of $17 \mathrm{cmH}_{2} \mathrm{O}$. We consequently 
consider that extending the duration of extubation failure in our population would not have changed our findings. In fact, weaning failure may not necessarily be directly induced by diaphragm dysfunction or ICU-AW, as several other causes could impair the weaning process $(34,35)$. Third, ICU-AW was determined using the MRC score and not with a dynamometer such as the measure of the adductor pollicis muscle function by magnetic stimulation of the ulnar nerve (36). We found that MRC was validated in ICU patients by much more studies than dynamometer and was also less time consuming and technically demanding. Lastly, for obvious technical reasons, this was a single-center study in a medical ICU with a limited number of patients, which may limit the generalizability of our findings concerning the prevalence of diaphragm dysfunction in other settings.

\section{Conclusion}

In patients undergoing their first SBT, we report a high prevalence of diaphragm dysfunction, which was associated with a higher rate of weaning failure and mortality. In contrast, the prevalence of ICU-AW was lower and not strongly correlated with diaphragm dysfunction, but was associated with a longer duration of MV and a longer ICU stay. Since the respective risk factors of ICU-AW and diaphragm dysfunction were also different, our findings raise the hypothesis that the respective potential contributors of ICU-acquired muscle weakness may have different consequences on the diaphragm and peripheral muscles with respect to the length of ICU stay. The association between diaphragm dysfunction and weaning failure demonstrated by our study fuels the notion that diaphragm dysfunction should be the object of prevention 
and possibly specific interventions (37-39). This should be the target of specific research studies. 


\section{References}

1. Fan E, Cheek F, Chlan L, Gosselink R, Hart N, Herridge MS, Hopkins RO, Hough CL, Kress JP, Latronico N, Moss M, Needham DM, Rich MM, Stevens RD, Wilson KC, Winkelman C, Zochodne DW, Ali NA, ATS Committee on ICU-acquired Weakness in Adults, American Thoracic Society. An official American Thoracic Society Clinical Practice guideline: the diagnosis of intensive care unit-acquired weakness in adults. Am J Respir Crit Care Med 2014;190:1437-1446.

2. Stevens RD, Marshall SA, Cornblath DR, Hoke A, Needham DM, de Jonghe B, Ali NA, Sharshar T. A framework for diagnosing and classifying intensive care unitacquired weakness. Crit Care Med 2009;37:S299-308.

3. Garnacho-Montero J, Amaya-Villar R, García-Garmendía JL, Madrazo-Osuna J, Ortiz-Leyba C. Effect of critical illness polyneuropathy on the withdrawal from mechanical ventilation and the length of stay in septic patients. Crit Care Med $2005 ; 33: 349-354$.

4. De Jonghe B, Bastuji-Garin S, Durand M-C, Malissin I, Rodrigues P, Cerf C, Outin H, Sharshar T, Groupe de Réflexion et d'Etude des Neuromyopathies en Réanimation. Respiratory weakness is associated with limb weakness and delayed weaning in critical illness. Crit Care Med 2007;35:2007-2015.

5. Kress JP, Hall JB. ICU-acquired weakness and recovery from critical illness. $N$ Engl J Med 2014;371:287-288.

6. Batt J, dos Santos CC, Cameron JI, Herridge MS. Intensive care unit-acquired weakness: clinical phenotypes and molecular mechanisms. Am J Respir Crit Care Med $2013 ; 187: 238-246$. 
7. Hermans G, Van Mechelen H, Clerckx B, Vanhullebusch T, Mesotten D, Wilmer A, Casaer MP, Meersseman P, Debaveye Y, Van Cromphaut S, Wouters PJ, Gosselink R, Van den Berghe G. Acute outcomes and 1-year mortality of intensive care unit-acquired weakness. A cohort study and propensity-matched analysis. Am J Respir Crit Care Med 2014;190:410-420.

8. Demoule A, Jung B, Prodanovic H, Molinari N, Chanques G, Coirault C, Matecki S, Duguet A, Similowski T, Jaber S. Diaphragm Dysfunction on Admission to ICU: Prevalence, Risk Factors and Prognostic Impact - a Prospective Study. Am J Respir Crit Care Med 2013; 188:213-9.

9. Jaber S, Petrof BJ, Jung B, Chanques G, Berthet J-P, Rabuel C, Bouyabrine H, Courouble P, Koechlin-Ramonatxo C, Sebbane M, Similowski T, Scheuermann V, Mebazaa A, Capdevila X, Mornet D, Mercier J, Lacampagne A, Philips A, Matecki S. Rapidly progressive diaphragmatic weakness and injury during mechanical ventilation in humans. Am J Respir Crit Care Med 2011;183:364-371.

10. Goligher EC, Fan E, Herridge MS, Murray A, Vorona S, Brace D, Rittayamai N, Lanys A, Tomlinson G, Singh JM, Bolz S-S, Rubenfeld GD, Kavanagh BP, Brochard LJ, Ferguson ND. Evolution of Diaphragm Thickness During Mechanical Ventilation: Impact of Inspiratory Effort. Am J Respir Crit Care Med 2015; 92:1080-8.

11. Kim WY, Suh HJ, Hong S-B, Koh Y, Lim C-M. Diaphragm dysfunction assessed by ultrasonography: influence on weaning from mechanical ventilation. Crit Care Med 2011;39:2627-2630.

12. Jiang J-R, Tsai T-H, Jerng J-S, Yu C-J, Wu H-D, Yang P-C. Ultrasonographic evaluation of liver/spleen movements and extubation outcome. Chest 2004;126:179- 
185.

13. Jung B, Moury PH, Mahul M, de Jong A, Galia F, Prades A, Albaladejo P, Chanques G, Molinari N, Jaber S. Diaphragmatic dysfunction in patients with ICUacquired weakness and its impact on extubation failure. Intensive Care Med $2015 ; 42: 853-61$.

14. De Jonghe B, Sharshar T, Lefaucheur J-P, Authier F-J, Durand-Zaleski I, Boussarsar M, Cerf C, Renaud E, Mesrati F, Carlet J, Raphaël J-C, Outin H, BastujiGarin S. Paresis acquired in the intensive care unit: a prospective multicenter study. JAMA 2002;288:2859-2867.

15. Dubé B-P, Demoule A, Mayaux J, Reuter D, Prodanovic H, Similowski T, Dres M. Ultrasonographically diagnosed diaphragmatic dysfunction and weaning failure from mechanical ventilation in critically ill patients. Intensive Care Med Exp 2015;3:1-2.

16. Boles J-M, Bion J, Connors A, Herridge M, Marsh B, Melot C, Pearl R, Silverman H, Stanchina M, Vieillard-Baron A, Welte T. Weaning from mechanical ventilation. Eur Respir J 2007;29:1033-1056.

17. Mills GH, Ponte J, Hamnegard CH, Kyroussis D, Polkey MI, Moxham J, Green M. Tracheal tube pressure change during magnetic stimulation of the phrenic nerves as an indicator of diaphragm strength on the intensive care unit. $B r J$ Anaesth $2001 ; 87: 876-884$.

18. Watson AC, Hughes PD, Louise Harris M, Hart N, Ware RJ, Wendon J, Green M, Moxham J. Measurement of twitch transdiaphragmatic, esophageal, and endotracheal tube pressure with bilateral anterolateral magnetic phrenic nerve 
stimulation in patients in the intensive care unit. Crit Care Med 2001;29:1325-1331.

19. Mills GH, Kyroussis D, Hamnegard CH, Polkey MI, Green M, Moxham J. Bilateral magnetic stimulation of the phrenic nerves from an anterolateral approach. Am J Respir Crit Care Med 1996;154:1099-1105.

20. Supinski GS, Callahan LA. Diaphragm weakness in mechanically ventilated critically ill patients. Crit Care 2013;17:R120.

21. Polkey MI, Kyroussis D, Hamnegard CH, Mills GH, Green M, Moxham J. Diaphragm strength in chronic obstructive pulmonary disease. Am J Respir Crit Care Med 1996;154:1310-1317.

22. Matamis D, Soilemezi E, Tsagourias M, Akoumianaki E, Dimassi S, Boroli F, Richard J-CM, Brochard L. Sonographic evaluation of the diaphragm in critically ill patients. Technique and clinical applications. Intensive Care Med 2013;39:801-810.

23. Goligher EC, Laghi F, Detsky ME, Farias P, Murray A, Brace D, Brochard LJ, Sebastien-Bolz S, Rubenfeld GD, Kavanagh BP, Ferguson ND. Measuring diaphragm thickness with ultrasound in mechanically ventilated patients: feasibility, reproducibility and validity. Intensive Care Med 2015; 192:1080-8.

24. American Thoracic Society/European Respiratory Society. ATS/ERS Statement on respiratory muscle testing. Am J Respir Crit Care Med 2002;166:518-624.

25. Levine S, Nguyen T, Taylor N, Friscia ME, Budak MT, Rothenberg P, Zhu J, Sachdeva R, Sonnad S, Kaiser LR, Rubinstein NA, Powers SK, Shrager JB. Rapid disuse atrophy of diaphragm fibers in mechanically ventilated humans. $N$ Engl $J$ Med 2008;358:1327-1335.

26. Hermans G, Agten A, Testelmans D, Decramer M, Gayan-Ramirez G. 
Increased duration of mechanical ventilation is associated with decreased diaphragmatic force: a prospective observational study. Crit Care 2010;14:R127.

27. Jung B, Nougaret S, Conseil M, Coisel Y, Futier E, Chanques G, Molinari N, Lacampagne A, Matecki S, Jaber S. Sepsis is associated with a preferential diaphragmatic atrophy: a critically ill patient study using tridimensional computed tomography. Anesthesiology 2014;120:1182-1191.

28. Divangahi M, Matecki S, Dudley RWR, Tuck SA, Bao W, Radzioch D, Comtois AS, Petrof BJ. Preferential diaphragmatic weakness during sustained Pseudomonas aeruginosa lung infection. Am J Respir Crit Care Med 2004;169:679686.

29. Wollersheim T, Woehlecke J, Krebs M, Hamati J, Lodka D, Luther-Schroeder A, Langhans C, Haas K, Radtke T, Kleber C, Spies C, Labeit S, Schuelke M, Spuler S, Spranger J, Weber-Carstens S, Fielitz J. Dynamics of myosin degradation in intensive care unit-acquired weakness during severe critical illness. Intensive Care Med 2014;40:528-538.

30. de Jonghe B, Lacherade J-C, Sharshar T, Outin H. Intensive care unit-acquired weakness: risk factors and prevention. Crit Care Med 2009;37:S309-315.

31. Andersen JL, Gruschy-Knudsen T, Sandri C, Larsson L, Schiaffino S. Bed rest increases the amount of mismatched fibers in human skeletal muscle. J Appl Physiol 1999;86:455-460.

32. De Jonghe B, Bastuji-Garin S, Sharshar T, Outin H, Brochard L. Does ICUacquired paresis lengthen weaning from mechanical ventilation? Intensive Care Med 2004;30:1117-1121. 
33. Llano-Diez M, Renaud G, Andersson M, Marrero HG, Cacciani N, Engquist H, Corpeño R, Artemenko K, Bergquist J, Larsson L. Mechanisms underlying ICU muscle wasting and effects of passive mechanical loading. Crit Care 2012;16:R209.

34. Perren A, Brochard L. Managing the apparent and hidden difficulties of weaning from mechanical ventilation. Intensive Care Med 2013; 39:1885-95.

35. Dres M, Teboul J-L, Monnet X. Weaning the cardiac patient from mechanical ventilation. Curr Opin Crit Care 2014;20:493-498.

36. Harris ML, Luo YM, Watson AC, Rafferty GF, Polkey MI, Green M, Moxham J. Adductor pollicis twitch tension assessed by magnetic stimulation of the ulnar nerve. Am J Respir Crit Care Med 2000;162:240-245.

37. Ahn B, Beaver T, Martin T, Hess P, Brumback BA, Ahmed S, Smith BK, Leeuwenburgh C, Martin AD, Ferreira LF. Phrenic nerve stimulation increases human diaphragm fiber force after cardiothoracic surgery. Am J Respir Crit Care Med 2014; 190:837-839.

38. Hooijman PE, Beishuizen A, de Waard MC, de Man FS, Vermeijden JW, Steenvoorde P, Bouwman RA, Lommen W, van Hees HWH, Heunks LMA, Dickhoff C, van der Peet DL, Girbes ARJ, Jasper JR, Malik FI, Stienen GJM, Hartemink KJ, Paul MA, Ottenheijm CAC. Diaphragm fiber strength is reduced in critically ill patients and restored by a troponin activator. Am J Respir Crit Care Med $2014 ; 189: 863-865$.

39. Doorduin J, Sinderby CA, Beck J, Stegeman DF, van Hees HWH, van der Hoeven JG, Heunks LMA. The calcium sensitizer levosimendan improves human diaphragm function. Am J Respir Crit Care Med 2012;185:90-95. 
40. McCool FD, Tzelepis GE. Dysfunction of the diaphragm. $N$ Engl $J$ Med 2012;366:932-942. 


\section{Tables}

Table 1. Patient characteristics on inclusion

\begin{tabular}{|c|c|}
\hline Men, $n(\%)$ & $52(68)$ \\
\hline Age, years & $57 \pm 16$ \\
\hline Body Mass Index, $\mathrm{kg} / \mathrm{m}^{2}$ & $25 \pm 6$ \\
\hline SOFA & $5 \pm 3$ \\
\hline SAPS 2 & $43 \pm 2$ \\
\hline Sepsis on admission, $n(\%)$ & $42(55)$ \\
\hline Duration of mechanical ventilation, days & $4(2-6)$ \\
\hline \multicolumn{2}{|l|}{ Reason for mechanical ventilation } \\
\hline Hypercapnic respiratory failure, $n(\%)$ & $9(12)$ \\
\hline Hypoxemic respiratory failure, $n(\%)$ & $22(29)$ \\
\hline Coma, $n(\%)$ & $22(29)$ \\
\hline Shock, $n(\%)$ & $23(30)$ \\
\hline \multicolumn{2}{|l|}{ Medical conditions } \\
\hline COPD, $n(\%)$ & $17(22)$ \\
\hline Cirrhosis, $n(\%)$ & $14(18)$ \\
\hline Diabetes, $n(\%)$ & $14(18)$ \\
\hline Current smoking, $(\%)$ & $37(49)$ \\
\hline \multicolumn{2}{|l|}{ Ventilator parameters } \\
\hline $\mathrm{FiO}_{2}(\%)$ & $34 \pm 5$ \\
\hline Pressure support level, $\mathrm{cmH}_{2} \mathrm{O}$ & $10 \pm 2$ \\
\hline Tidal volume, $\mathrm{ml} / \mathrm{kg}$ ideal body weight & $6.9 \pm 1.9$ \\
\hline PEEP, $\mathrm{cmH}_{2} \mathrm{O}$ & $6 \pm 1$ \\
\hline \multicolumn{2}{|l|}{ Clinical parameters } \\
\hline Respiratory rate, breath/min & $23 \pm 5$ \\
\hline Mean arterial pressure, $\mathrm{mmHg}$ & $83 \pm 17$ \\
\hline Heart rate, $\min ^{-1}$ & $92 \pm 18$ \\
\hline \multicolumn{2}{|l|}{ Blood gases } \\
\hline $\mathrm{pH}$ & $7.43 \pm 0.08$ \\
\hline $\mathrm{PaCO}_{2}, m m H g$ & $40 \pm 9$ \\
\hline $\mathrm{PaO}_{2}, m m H g$ & $101 \pm 34$ \\
\hline $\mathrm{PaO}_{2} / \mathrm{FiO}_{2}$ & $292 \pm 104$ \\
\hline Lactate, $\mathrm{mmol} / \mathrm{L}$ & $1.6 \pm 0.7$ \\
\hline
\end{tabular}

Continuous variables are expressed as mean \pm standard deviation or median (interquartile range) and categorical variables are expressed as absolute value (\%).

SAPS 2, Simplified Acute Physiology Score; SOFA, Sequential Organ Failure Assessment score; COPD, Chronic Obstructive Pulmonary Disease; PEEP, Positive End-Expiratory Pressure; $\mathrm{FiO}_{2}$, Inspired oxygen fraction; $\mathrm{PaO}_{2} / \mathrm{FiO}_{2}$, ratio of arterial oxygen tension to inspired oxygen fraction 
Table 2. Patient characteristics according to the presence of diaphragm dysfunction or ICU-AW at inclusion

\begin{tabular}{|c|c|c|c|c|c|c|}
\hline & $\begin{array}{c}\text { Diaphragm } \\
\text { Dysfunction } \\
\mathrm{n}=48\end{array}$ & $\begin{array}{c}\text { No Diaphragm } \\
\text { Dysfunction } \\
n=28\end{array}$ & $\mathrm{p}$ & $\begin{array}{c}\text { ICU-AW } \\
n=26\end{array}$ & $\begin{array}{c}\text { No ICU-AW } \\
n=50\end{array}$ & $\mathrm{p}$ \\
\hline \multicolumn{7}{|l|}{ Demographic data } \\
\hline Men, $n(\%)$ & $32(67)$ & $20(71)$ & 0.67 & $17(65)$ & $35(70)$ & 0.68 \\
\hline Age, years & $61 \pm 13$ & $51 \pm 18$ & 0.01 & $61 \pm 12$ & $56 \pm 17$ & 0.16 \\
\hline Body Mass Index, $\mathrm{kg} / \mathrm{m}^{2}$ & $25 \pm 6$ & $26 \pm 4$ & 0.75 & $24 \pm 3$ & $26 \pm 6$ & 0.08 \\
\hline \multicolumn{7}{|l|}{ Medical conditions } \\
\hline Heart failure, $n(\%)$ & $10(21)$ & $2(7)$ & 0.11 & $3(12)$ & $9(18)$ & 0.46 \\
\hline COPD, $n(\%)$ & $10(21)$ & $2(7)$ & 0.11 & $2(8)$ & $10(20)$ & 0.16 \\
\hline Cirrhosis, $n(\%)$ & $8(17)$ & $6(21)$ & 0.76 & $9(35)$ & $5(10)$ & 0.01 \\
\hline Diabetes, $n(\%)$ & $9(19)$ & $5(18)$ & 0.92 & $5(19)$ & $9(18)$ & 0.90 \\
\hline Current smoking, $n(\%)$ & $25(52)$ & $12(43)$ & 0.44 & $12(46)$ & $25(50)$ & 0.75 \\
\hline \multicolumn{7}{|l|}{ On admission } \\
\hline SOFA & $5 \pm 3$ & $5 \pm 3$ & 0.80 & $6 \pm 3$ & $5 \pm 3$ & 0.04 \\
\hline SAPS 2 & $46 \pm 23$ & $37 \pm 21$ & 0.09 & $47 \pm 23$ & $41 \pm 22$ & 0.11 \\
\hline Sepsis, $n(\%)$ & $25(52)$ & $17(61)$ & 0.46 & $11(42)$ & $31(62)$ & 0.10 \\
\hline \multicolumn{7}{|l|}{ Reason for admission } \\
\hline Hypercapnic respiratory failure, $n(\%)$ & $7(15)$ & $2(7)$ & 0.47 & $1(4)$ & $8(16)$ & 0.15 \\
\hline Hypoxemic respiratory failure, $n(\%)$ & $17(35)$ & $5(18)$ & 0.12 & $10(38)$ & $12(24)$ & 0.20 \\
\hline Shock, $n(\%)$ & $17(35)$ & $6(21)$ & 0.30 & $9(35)$ & $14(28)$ & 0.60 \\
\hline Coma, $n(\%)$ & $7(15)$ & $15(54)$ & 0.001 & $6(23)$ & $16(32)$ & 0.42 \\
\hline Duration of MV prior to inclusion, days & $5(2-7)$ & $3(1-5)$ & 0.04 & $6(4-8)$ & $3(1-5)$ & 0.01 \\
\hline \multicolumn{7}{|l|}{ Medication exposure prior to inclusion } \\
\hline Propofol, $n(\%)$ & $27(57)$ & $13(46)$ & 0.36 & $9(35)$ & $31(63)$ & 0.02 \\
\hline Neuromuscular blocker, $n(\%)$ & $9(19)$ & $2(7)$ & 0.16 & $3(12)$ & $8(16)$ & 0.58 \\
\hline Midazolam, $n(\%)$ & $14(30)$ & $11(39)$ & 0.40 & $9(35)$ & $16(33)$ & 0.86 \\
\hline Sufentanil, $n(\%)$ & $26(55)$ & $11(39)$ & 0.18 & $12(46)$ & $25(51)$ & 0.69 \\
\hline Corticosteroids, $n(\%)$ & $6(13)$ & $3(11)$ & 0.79 & $5(19)$ & $4(8)$ & 0.16 \\
\hline \multicolumn{7}{|l|}{ Diaphragm assessment } \\
\hline Ptr,stim, $\mathrm{CmH}_{2} \mathrm{O}$ & $6.4 \pm 2.4$ & $16.5 \pm 5.5$ & $<0.001$ & $9.3 \pm 6.6$ & $10.5 \pm 6.0$ & 0.42 \\
\hline $\mathrm{T}_{\mathrm{DE}}, m m$ & $2.11 \pm 0.54$ & $2.20 \pm 0.63$ & 0.54 & $2.01(0.50)$ & $2.21(0.60)$ & 0.13 \\
\hline Diaphragm dysfunction, $\%$ & - & - & & $16(62)$ & $32(67)$ & 0.83 \\
\hline TFdi, $\%$ & $21 \pm 9$ & $40 \pm 11$ & $<0.001$ & $26 \pm 14$ & $29 \pm 13$ & 0.40 \\
\hline Excursion, $\mathrm{cm}$ & $0.94 \pm 0.46$ & $1.10 \pm 0.32$ & 0.15 & $0.87 \pm 0.42$ & $1.06 \pm 0.40$ & 0.11 \\
\hline \multicolumn{7}{|l|}{ Limb muscle assessment } \\
\hline MRC score & $47 \pm 13$ & $50 \pm 11$ & 0.35 & $34 \pm 13$ & $55 \pm 4$ & $<0.001$ \\
\hline ICU-AW, \% & $16(33)$ & $10(36)$ & 0.83 & - & - & \\
\hline \multicolumn{7}{|l|}{ Ventilator settings at inclusion } \\
\hline Pressure support level, $\mathrm{CmH}_{2} \mathrm{O}$ & $10 \pm 2$ & $10 \pm 2$ & 0.59 & $10 \pm 3$ & $10 \pm 2$ & 0.94 \\
\hline PEEP, $\mathrm{CmH}_{2} \mathrm{O}$ & $6 \pm 1$ & $6 \pm 1$ & 0.77 & $5 \pm 1$ & $6 \pm 1$ & 0.09 \\
\hline Tidal volume, $\mathrm{ml} / \mathrm{kg} I B W$ & $6.4 \pm 1.7$ & $7.7 \pm 2.0$ & 0.005 & $6.9 \pm 1.9$ & $7.0 \pm 1.9$ & 0.79 \\
\hline
\end{tabular}

Data are expressed as mean \pm standard deviation or median (interquartile range) or $n(\%)$. 
ICU-AW, Intensive care unit-acquired weakness; SAPS 2, Simplified Acute Physiology Score; SOFA, Sequential Organ Failure Assessment score; COPD, Chronic Obstructive Pulmonary Disease; MV: Mechanical ventilation; $\mathrm{T}_{\mathrm{DE}}$, Endexpiratory diaphragm thickness; TFdi, Diaphragm thickening fraction; Excursion, Maximum excursion of the diaphragm; Ptr,stim, Endotracheal tube pressure induced by bilateral phrenic nerve stimulation during airway occlusion; MRC, Medical Research Council. 
Table 3. Patient characteristics according to weaning outcome

\begin{tabular}{|c|c|c|c|}
\hline & $\begin{array}{c}\text { Weaning failure } \\
n=33(43 \%)\end{array}$ & $\begin{array}{c}\text { Weaning success } \\
n=43(57 \%)\end{array}$ & $\mathbf{p}$ \\
\hline Men, $n(\%)$ & $23(70)$ & $29(67)$ & 0.83 \\
\hline Age, years & $63 \pm 12$ & $54 \pm 17$ & 0.01 \\
\hline Body Mass Index, $\mathrm{kg} / \mathrm{m}^{2}$ & $26 \pm 6$ & $25 \pm 5$ & 0.19 \\
\hline SOFA & $5 \pm 2$ & $5 \pm 3$ & 0.77 \\
\hline SAPS2 & $46 \pm 23$ & $40 \pm 21$ & 0.23 \\
\hline MV before inclusion, days & $6(4-10)$ & $3(1-5)$ & $<0.001$ \\
\hline \multicolumn{4}{|l|}{ Reason for MV } \\
\hline Hypercapnic respiratory failure, $n(\%)$ & $6(18)$ & $3(7)$ & 0.17 \\
\hline Hypoxemic respiratory failure, $n(\%)$ & $12(36)$ & $10(23)$ & 0.31 \\
\hline Shock, $n(\%)$ & $10(30)$ & $13(30)$ & 0.99 \\
\hline Coma, $n(\%)$ & $5(15)$ & $17(40)$ & 0.02 \\
\hline \multicolumn{4}{|l|}{ Medical conditions } \\
\hline Chronic heart failure, $n(\%)$ & $4(12)$ & $8(19)$ & 0.44 \\
\hline COPD, $n(\%)$ & $8(24)$ & $4(9)$ & 0.08 \\
\hline Cirrhosis, $n(\%)$ & $9(27)$ & $5(12)$ & 0.23 \\
\hline Diabetes, $n(\%)$ & $7(21)$ & $7(16)$ & 0.77 \\
\hline Current smoking, $n(\%)$ & $17(52)$ & $20(47)$ & 0.81 \\
\hline \multicolumn{4}{|l|}{ Physiological variables } \\
\hline Mean arterial pressure, $\mathrm{mmHg}$ & $82 \pm 20$ & $84 \pm 15$ & 0.60 \\
\hline Heart rate, $\mathrm{min}^{-1}$ & $95 \pm 17$ & $89 \pm 18$ & 0.15 \\
\hline Respiratory rate, breath/min & $24 \pm 5$ & $22 \pm 5$ & 0.08 \\
\hline \multicolumn{4}{|l|}{ Ventilator settings } \\
\hline Pressure support level, $\mathrm{cmH}_{2} \mathrm{O}$ & $10 \pm 3$ & $10 \pm 2$ & 0.36 \\
\hline PEEP, $\mathrm{CmH}_{2} \mathrm{O}$ & $6 \pm 1$ & $6 \pm 1$ & 0.68 \\
\hline Tidal volume, $\mathrm{ml} / \mathrm{kg} I B W$ & $6 \pm 1$ & $8 \pm 2$ & 0.001 \\
\hline \multicolumn{4}{|l|}{ Diaphragm activity } \\
\hline TFdi, $\%$ & $19 \pm 9$ & $35 \pm 12$ & $<0.001$ \\
\hline Excursion, $\mathrm{cm}$ & $0.82 \pm 0.42$ & $1.12 \pm 0.37$ & 0.01 \\
\hline $\mathrm{T}_{\mathrm{DE}}, m m$ & $2.20 \pm 0.60$ & $2.10 \pm 0.58$ & 0.42 \\
\hline \multicolumn{4}{|l|}{ Arterial blood gases } \\
\hline $\mathrm{PaO}_{2} / \mathrm{FiO}_{2}, m m H g$ & $256(87)$ & $322(108)$ & 0.01 \\
\hline $\mathrm{PaCO}_{2}, m m H g$ & $43 \pm 10$ & $37 \pm 7$ & 0.02 \\
\hline \multicolumn{4}{|l|}{ Diaphragm and limb function } \\
\hline Ptr,stim < $11 \mathrm{cmH}_{2} \mathrm{O}, n(\%)$ & $31(94)$ & $17(40)$ & $<0.001$ \\
\hline Ptr,stim, $\mathrm{CmH}_{2} \mathrm{O}$ & $5.9 \pm 2.7$ & $13.3 \pm 6.2$ & $<0.001$ \\
\hline Score MRC $<48, n(\%)$ & $15(46)$ & $11(26)$ & 0.07 \\
\hline MRC score & $43 \pm 14$ & $51 \pm 10$ & 0.01 \\
\hline
\end{tabular}

Data are expressed as mean \pm standard deviation or median (interquartile range) or $\mathrm{n}(\%)$.

SAPS 2, Simplified Acute Physiology Score; SOFA, Sequential Organ Failure Assessment score; MV, Mechanical ventilation; COPD, Chronic Obstructive Pulmonary Disease; PEEP, Positive end-expiratory pressure; IBW, Ideal body weight; $\mathrm{FiO}_{2}$, Inspired oxygen fraction; $\mathrm{PaO}_{2} / \mathrm{FiO}_{2}$, ratio of arterial oxygen tension to inspired oxygen fraction; Ptr,stim, Endotracheal tube pressure induced by bilateral phrenic nerve stimulation during airway occlusion; MRC, Medical Research Council; TFdi, Diaphragm thickening fraction; $T_{D E}$, End expiratory diaphragm thickness; Excursion, Maximum excursion of the diaphragm. 
Table 4. Clinical outcome according to the presence of diaphragm dysfunction and ICU-acquired weakness

\begin{tabular}{|c|c|c|c|c|c|c|c|}
\hline & \multirow{2}{*}{$\begin{array}{c}\begin{array}{c}\text { Overall } \\
\text { population }\end{array} \\
\mathrm{n}=76\end{array}$} & \multicolumn{2}{|c|}{$\begin{array}{l}\text { Diaphragm } \\
\text { dysfunction }\end{array}$} & \multirow[b]{2}{*}{$\mathrm{p}$} & \multicolumn{2}{|c|}{$\begin{array}{c}\text { ICU } \\
\text { Acquired Weakness }\end{array}$} & \multirow[b]{2}{*}{$\mathrm{p}$} \\
\hline & & $\begin{array}{c}\text { Yes } \\
\mathrm{n}=48\end{array}$ & $\begin{array}{c}\text { No } \\
\mathrm{n}=28\end{array}$ & & $\begin{array}{c}\text { Yes } \\
\mathrm{n}=26\end{array}$ & $\begin{array}{c}\mathrm{No} \\
\mathrm{n}=50\end{array}$ & \\
\hline Difficult weaning, $n(\%)$ & $25(33)$ & $23(48)$ & $2(7)$ & $<0.001$ & $11(42)$ & $14(28)$ & 0.30 \\
\hline Prolonged weaning, $n(\%)$ & $8(10)$ & $8(17)$ & $0(0)$ & 0.02 & $4(15)$ & $4(8)$ & 0.43 \\
\hline Total duration of MV, days & $5(2-10)$ & $7(4-12)$ & $4(1-6)$ & 0.04 & $7(4-12)$ & $5(1-7)$ & 0.04 \\
\hline Length of ICU stay, days & $8(4-15)$ & $10(5-16)$ & $6(3-10)$ & 0.05 & $9(6-17)$ & $6(3-14)$ & 0.17 \\
\hline Length of hospital stay, days & $21(9-30)$ & $23(15-32)$ & $18(6-29)$ & 0.09 & $26(14-37)$ & $19(8-28)$ & 0.008 \\
\hline ICU mortality, $n(\%)$ & $8(10)$ & $8(17)$ & $0(0)$ & 0.02 & $5(19)$ & $3(6)$ & 0.11 \\
\hline Hospital mortality, $n(\%)$ & $12(16)$ & $11(23)$ & $1(4)$ & 0.04 & $7(27)$ & $5(10)$ & 0.09 \\
\hline
\end{tabular}

Data are expressed as median (interquartile range) or $\mathrm{n}(\%)$.

$\mathrm{MV}$, Mechanical ventilation; ICU, Intensive care unit 


\section{Figure legends}

Figure 1. Study flow-chart

ICU-AW, intensive care unit-acquired weakness. PEEP, positive end expiratory pressure.

Figure 2. Correlation analysis between the Medical Research Council score and either the change in tracheal pressure induced by bilateral phrenic nerve stimulation (2A) or the diaphragm thickening fraction (2B). Dashed lines represent the cut-off of Ptr,stim to diagnose diaphragm dysfunction in the critically ill (-11 $\left.\mathrm{cm} \mathrm{H}_{2} \mathrm{O}\right)(8)$, the cut-off of diaphragm thickening fraction to diagnose diaphragm dysfunction (40) and the cut-off of MRC to diagnose intensive care unit-acquired weakness (48).

Figure 3. Histogram showing the respective prevalence of intensive care unit (ICU)-acquired weakness and diaphragm dysfunction according to the international weaning classification categories. ${ }^{*} \mathrm{p}<0.05$ (Chi-square test between three groups).

Figure 4. Forest plot showing the factors significantly associated with weaning failure: results of four multivariate logistic regressions, each separately including: Ptr,stim, TFdi, EXdi or MRC score.

The Forest plot shows that an increase in the duration of mechanical ventilation prior to inclusion was independently associated with weaning failure in the four models. Diaphragm dysfunction was independently associated with weaning failure 
in the models including Ptr,stim (each 1 unit increase of Ptr,stim decreased the risk of weaning failure, Odds Ratio (OR) 0.60, 95\% Confidence Interval (CI) 0.45-0.79, $\mathrm{p}<0.001$ ), TFdi (each 1 unit increase of TFdi decreased the risk of weaning failure, OR 0.84, 95\% CI 0.76-0.92, p<0.001) and EXdi (each 1 unit increase of TFdi decreased the risk of weaning failure, OR $0.15,95 \%$ CI $0.02-0.94, p=0.04)$. MRC score was not associated with weaning failure (OR 0.96, 95\% CI 0.91-1.02, $\mathrm{p}<0.20$ ).

In the model with EXdi, data were available for 58/76 patients.

MV, mechanical ventilation; $\mathrm{PaCO}_{2}$, partial arterial carbon dioxide tension, TFdi, diaphragm thickening fraction; EXdi, Diaphragmatic excursion; Ptr,stim, endotracheal tube pressure induced by bilateral phrenic nerve stimulation during airway occlusion; MRC, Medical Research Council score. 


\section{Page 69 of 86}

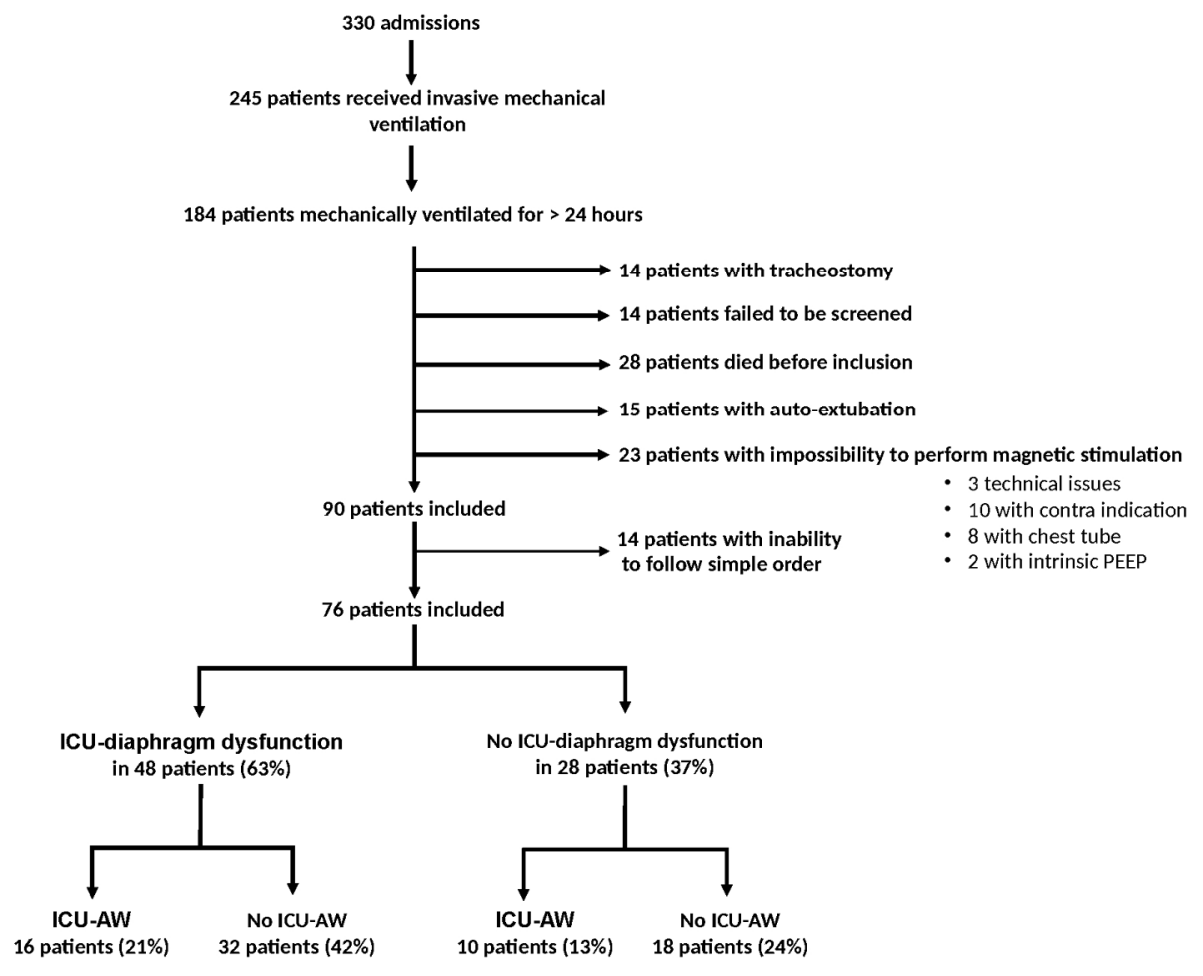

Figure 1

$254 \times 190 \mathrm{~mm}(200 \times 200 \mathrm{DPI})$ 


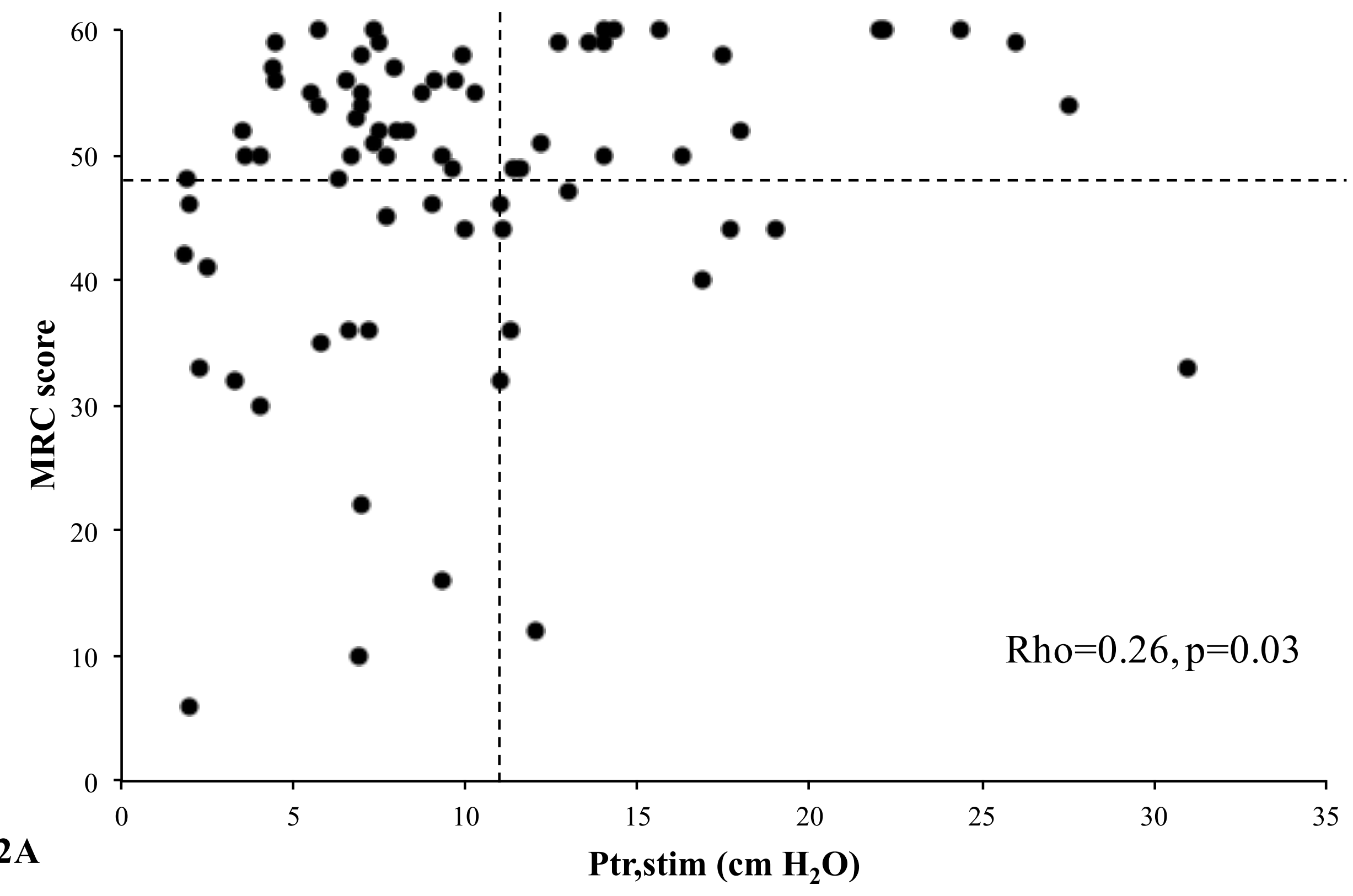




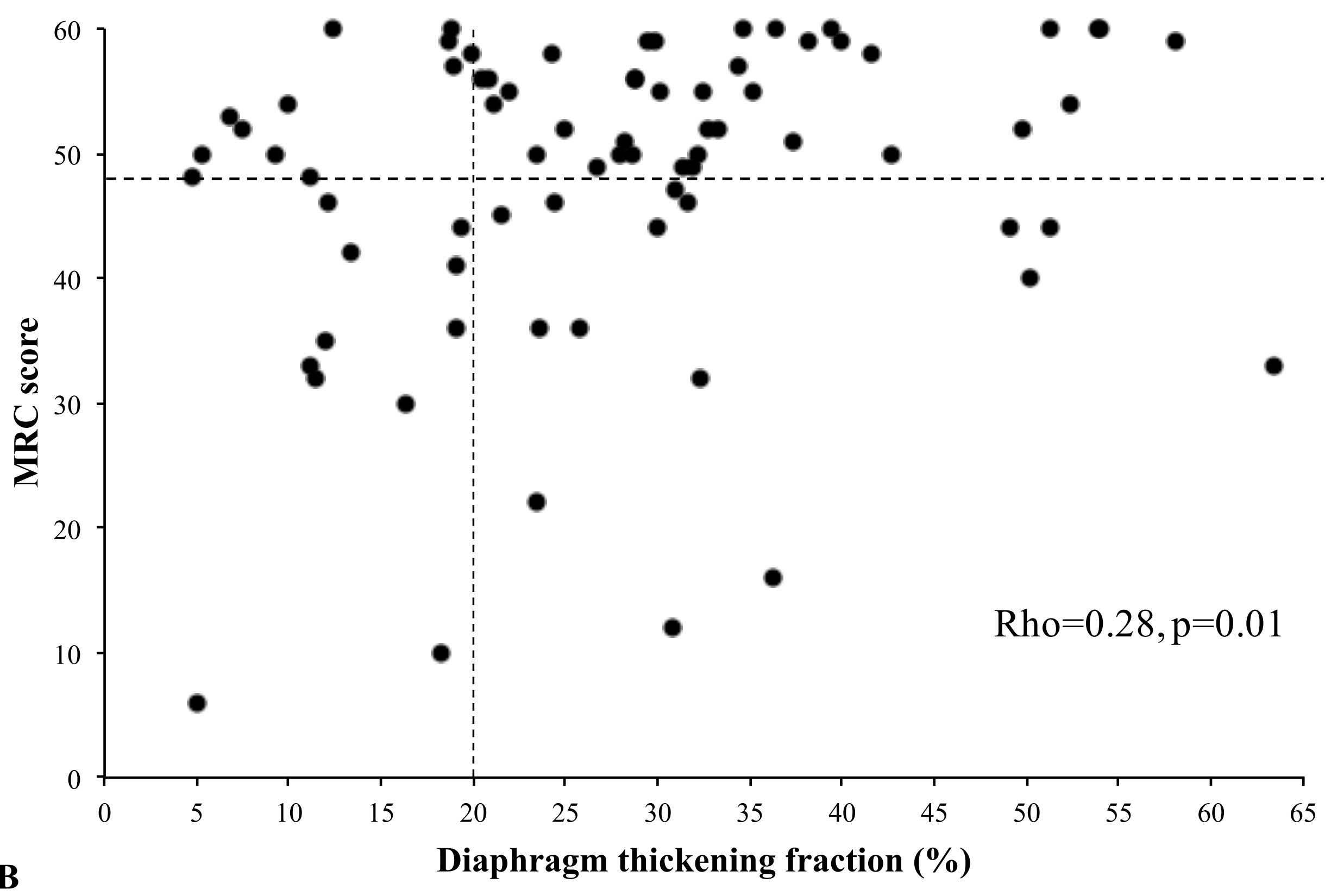




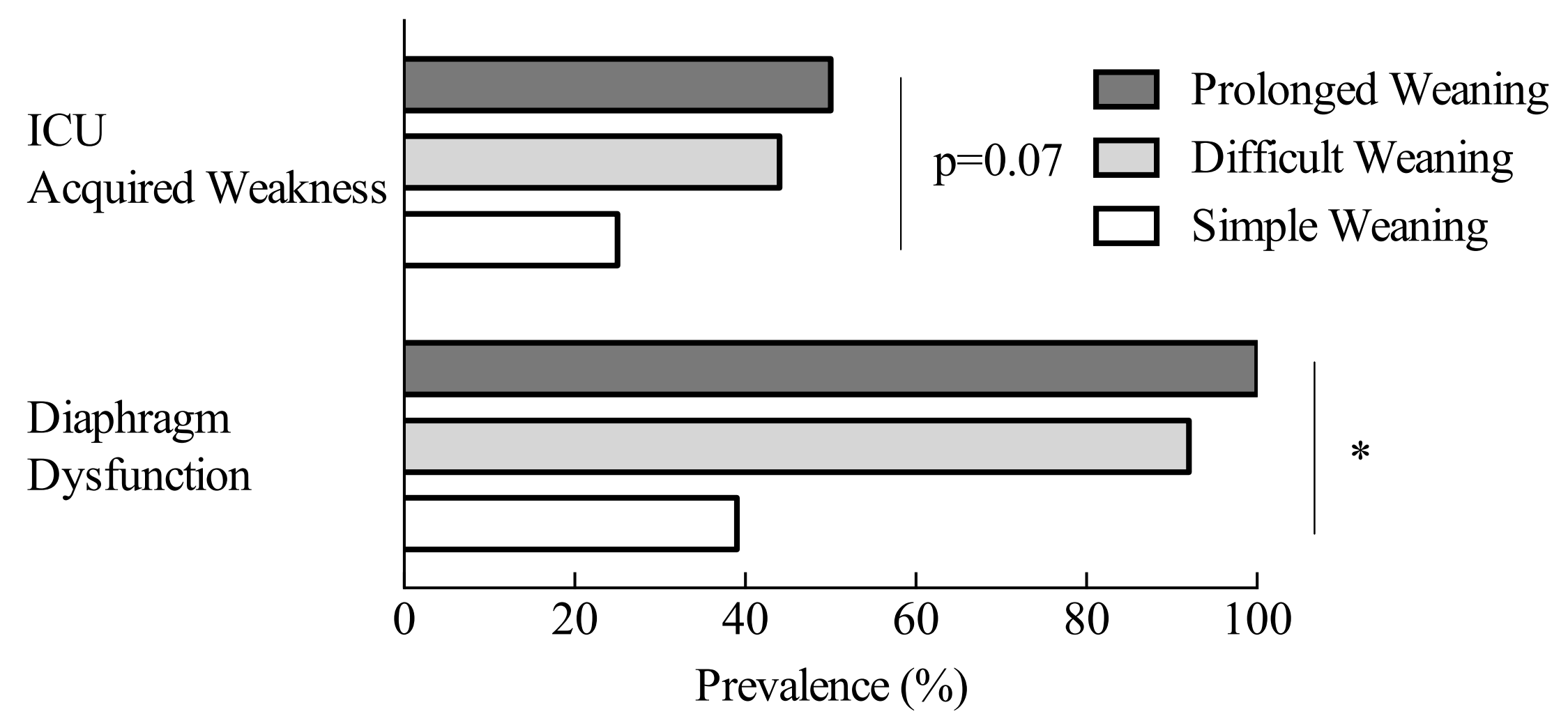




\section{Page 73 of 86}

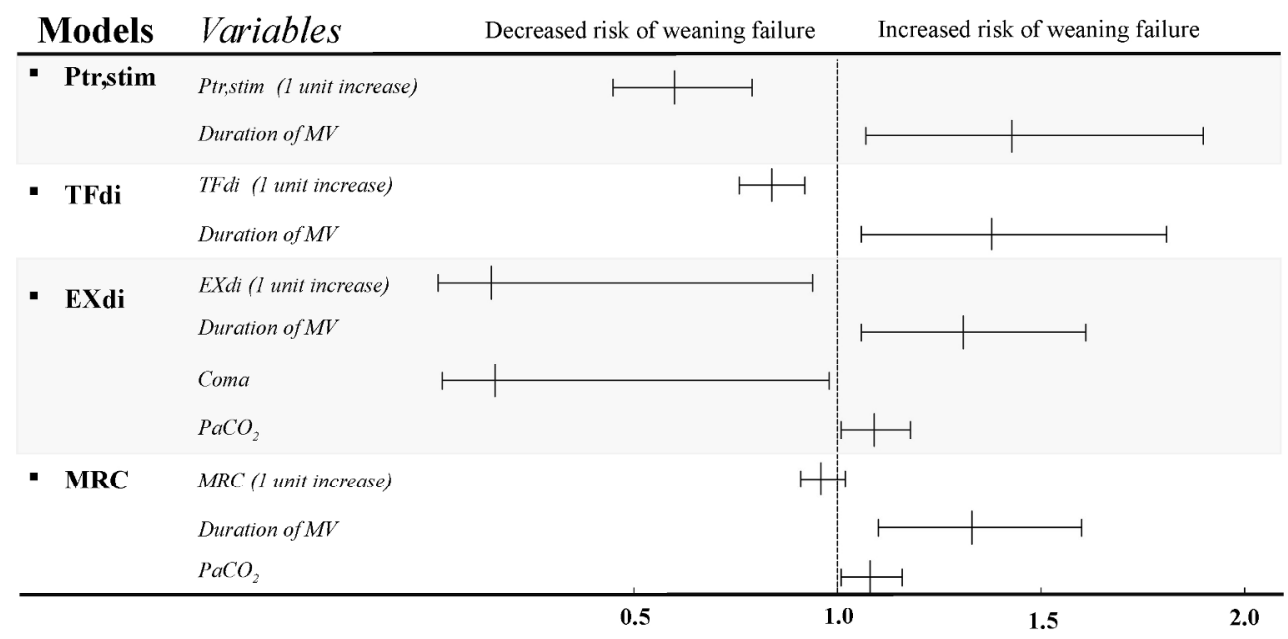

Figure 4

$338 \times 190 \mathrm{~mm}(200 \times 200$ DPI $)$ 


\section{Coexistence and impact of limb muscle and diaphragm weakness at time of liberation from mechanical ventilation in medical ICU patients}

Martin Dres, MD, Bruno-Pierre Dubé, MD, Julien Mayaux MD, Julie Delemazure, MD, Danielle Reuter, Laurent Brochard, MD, PhD, Thomas Similowski, MD, PhD; Alexandre Demoule, MD, PhD

\section{Online supplement}

\section{Methods}

\section{Patients}

Patients were eligible for inclusion in the study when they fulfilled the readiness criteria to start a spontaneous breathing trial (SBT) (1). Those criteria were: (1) adequate oxygenation as stated by a $\mathrm{SpO} 2>90 \%$ on a fraction of inspired oxygen $(\mathrm{FiO} 2) \leq 40 \%$ and positive end expiratory pressure (PEEP) $\leq 8 \mathrm{cmH}_{2} \mathrm{O},(2)$ adequate pulmonary function as stated by a respiratory rate $\leq 35 / \mathrm{min}$, (3) a cooperative cognitive state, (4) stable cardiovascular status as stated by a systolic arterial blood pressure of $90-160 \mathrm{mmHg}$ without or minimal vasopressors and heart rate $\leq 140 / \mathrm{min}$. Exclusion criteria were: inability to follow simple order enabling to perform MRC score and contraindications or impossibility to perform magnetic stimulation of the phrenic nerves (cardiac pacemaker or implanted defibrillator, cervical implants), use of neuromuscular blocking agents within the 24 hours preceding the first diaphragm function assessment (with the 
exception of succinylcholine used during rapid-sequence induction of anaesthesia for intubation), pre-existing neuromuscular disorders, factors possibly interfering with tracheal pressure measurements in response to phrenic stimulation (multiple functioning chest drains, intrinsic positive end expiratory pressure). Finally, age less than 18 years, known pregnancy, and a decision to withhold life-sustaining treatment were also exclusion criteria.

\section{Protocol}

\section{Spontaneous breathing trial protocol}

When the patients fulfilled the readiness-to-wean criteria, a 30-min SBT was performed with the patient connected to the ventilator (pressure support level $7 \mathrm{cmH}_{2} \mathrm{O}$, zero end expiratory pressure). The SBT was considered to be a failure if at least one the following criteria was present: (1) blood oxygen saturation $\left(\mathrm{SpO}_{2}\right)$ of $<90 \%$ with a fraction of inspired oxygen $\left(\mathrm{FiO}_{2}\right) \geq 50 \%$; (2) acute respiratory distress $(\mathrm{RR} \geq 40 / \mathrm{min}$, agitation, cyanosis); (3) systolic arterial blood pressure of $\geq 180 \mathrm{mmHg}$; (4) cardiac arrhythmias; (5) respiratory acidosis $[\mathrm{pH}<7.32$ with an arterial carbon dioxide tension $\left(\mathrm{PaCO}_{2}\right)$ of $\geq 50 \mathrm{mmHg}$. If none of these failure criteria was present, the SBT was considered as successfully completed and the patient was extubated. The decision was taken by the attending physician. If the patient did not meet the predefined clinical intolerance criteria but was not extubated after completion of the SBT, he was considered as a weaning failure. The patient was reconnected if signs of intolerance (see above) were present. The separation from the ventilator and the endotracheal tube was considered as a success (weaning success) when spontaneous breathing could be sustained without any form of ventilatory support until $48 \mathrm{~h}$ after extubation. Conversely, cases of failure 
included patients who failed the SBT and patients requiring reintubation or any form of ventilator support (including non-invasive ventilation for post-extubation acute respiratory failure) during the first $48 \mathrm{~h}$ after extubation (weaning failure). Patients were only studied once, at the first SBT.

Assessment of the diaphragm pressure generating capacity with the phrenic nerves stimulation

Diaphragm pressure generating capacity was assessed in terms of the changes in endotracheal tube pressure induced by bilateral phrenic nerve stimulation during airway occlusion (Ptr,stim) (2-4). Phrenic nerve stimulation was performed by bilateral anterior magnetic stimulation. Briefly, two figure-of-eight coils connected to a pair of Magstim ${ }^{\circledR}$ 200 stimulators (The Magstim Company, Dyfed, UK) were positioned immediately posterior to the sternomastoid muscles at the level of the cricoid cartilage. Stimulations were delivered at the maximum output intensity of the stimulator $(100 \%)$ that is known to consistently result in supramaximal phrenic contraction $(3,5-7)$. The patients were studied in a standardized semi-recumbent position, as follows: end-expiratory pressure was set to zero and the patient was allowed to exhale during an end-expiratory pause. Intrinsic positive end expiratory pressure was found when at relaxed end-expiration, the endotracheal pressure could not reach the zero baseline while the endotracheal tube was disconnected from the ventilator, manually occluded and by checking the absence of respiratory effort. While the endotracheal tube was manually occluded, bilateral anterolateral magnetic stimulation was performed. The absence of active respiratory efforts in response to stimulation was determined by checking the stability of the airway pressure signal. Two operators were required to achieve both stimulation and 
measurements. After determining the optimal position of the coils, at least three stimulations were performed at $100 \%$ of maximal output allowed by the stimulator. Stimulations were separated by at least $60-\mathrm{sec}$ to avoid superposition. The average of the three measures was taken into account for analysis. Ptr,stim was defined as the amplitude of the negative pressure wave following stimulation, taken from baseline to peak. It was measured at the proximal external end of the endotracheal tube, using a linear differential pressure transducer (MP45 $\pm 100 \mathrm{cmH} 2 \mathrm{O}$, Validyne, Northridge, Calif., USA). The pressure signal was sampled and digitized at $128 \mathrm{~Hz}$ (MP30, Biopac Systems, Santa Barbara, Calif., USA or Powerlab, AD Instruments, Bella Vista, Australia) for subsequent data analysis.

\section{Assessment of diaphragmatic thickening with ultrasound}

Ultrasound measurements were performed by two investigators after a 2 months training session in diaphragmatic ultrasound. Inter-observer reliability of the ultrasound measurements was assessed using intra-class correlation (ICC) on a sample of the first 20 patients enrolled in the study while the two observers were blinded to each other's measurements. ICC for the measurements of end-expiratory diaphragm thickness $\left(\mathrm{T}_{\mathrm{DE}}\right)$ and end-inspiratory diaphragm thickness $\left(\mathrm{T}_{\mathrm{DI}}\right)$ were measured using electronic calipers. ICC for $\mathrm{T}_{\mathrm{DI}}, \mathrm{T}_{\mathrm{DE}}$ and diaphragm thickening fraction (TFdi) were respectively: $\mathrm{ICC}=0.95$ $(\mathrm{p}<0.001), \mathrm{ICC}=0.96(\mathrm{p}<0.001)$ and $\mathrm{ICC}=0.87(\mathrm{p}<0.001)$.

Ultrasound assessment of the diaphragm thickening was performed using a 4-12 MHz linear array transducer (Sparq ultrasound system, Phillips, Philips Healthcare, Andover, MA, USA). As previously reported $(8,9)$, the probe was placed perpendicular to the right chest wall, at the midaxillary line between the $9^{\text {th }}$ and $10^{\text {th }}$ right intercostal 
spaces (at the level of the zone of apposition) and the right diaphragm was identified as a three-layered structure comprising two hyperechoic lines representing the pleural and peritoneal membranes and an middle hypoechoic layer representing the diaphragmatic muscle fibers. Using M-mode at a sweep speed of $10 \mathrm{~mm} / \mathrm{s}$, at least three spontaneous quiet breathing cycles were recorded and the image was frozen. Diaphragm thickness was measured at end-expiration $\left(\mathrm{T}_{\mathrm{DE}}\right)$ and end-inspiration $\left(\mathrm{T}_{\mathrm{DI}}\right)$ using electronic calipers. The thickening fraction of the diaphragm (TFdi) was calculated offline as $\left(\mathrm{T}_{\mathrm{DI}}-\mathrm{T}_{\mathrm{DE}}\right) / \mathrm{T}_{\mathrm{DE}}$.

Diaphragm excursion was measured using a 2-6 Mhz broadband curved array transducer, with the same ultrasound machine. The probe was placed below the right costal margin and directed medially and cephalad. The diaphragm was identified as the hyperechoic linear structure cephalad to the liver, and its excursion measured using Mmode.

For all measurement, at least three valid breathing cycles were recorded, and the average of the individual values was reported. Ultrasounds were performed by one of the investigators (either B.P.D or M.D.).

\section{Study Protocol}

Just before to start the SBT, we analysed the diaphragm and limbs muscles strength during 3 steps in a random basis. During the first step, we recorded Ptr,stim with the phrenic nerves stimulation technic while the patient was briefly disconnected from the ventilator in order to measure the changes in endotracheal tube pressure induced by bilateral phrenic nerve stimulation during airway occlusion. During the second step, we measured with diaphragm ultrasound, end inspiratory and expiratory diaphragm thickness 
and maximal diaphragm excursion. During the third step, we evaluated the limbs muscles strength with the Medical Research Council score. During the second and the third step, patients were ventilated under pressure support with a level of assistance set to target a tidal volume of 6 to $8 \mathrm{ml} / \mathrm{kg}$ of ideal body weight. PEEP was not modified during the measurements. In our unit, PEEP is routinely set at around $5 \mathrm{cmH}_{2} \mathrm{O}$.

\section{Clinical data collection}

Demographic data, severity scores, organ dysfunction-related variables, physiological data, blood gas data, presence of sepsis (10) and medications were recorded. The durations of mechanical ventilation, ICU stay and hospital stay, ICU and hospital mortality were also recorded. The ICU mortality was censored at 60 days and hospital mortality at 90 days. We also defined difficult and prolonged weaning according the International Weaning Conference (1). Difficult weaning included patients who required up to three SBT or as long as 7 days from the first SBT to achieve successful weaning and prolonged weaning, includes patients who require more than three SBT or 7 days of weaning after the first SBT (1).

\section{Statistical analysis}

Potential risk factors for the presence of diaphragm dysfunction, ICU-AW and weaning failure were assessed with univariate analysis using only factors present before the SBT. Then, logistic regression models were built for each occurrence (diaphragm dysfunction, ICU-AW and weaning failure) as follows:

Impact of exposure variables on the occurrence of ICU-AW

To assess the impact of exposure variables on the occurrence of ICU-AW, forward logistic regression models were built. The dependent variable was the occurrence of ICU- 
AW at time of liberation from mechanical ventilation (the day of the first SBT). Due to the number of events in the cohort, the number of exposure variables entering into the model was limited (11). Only the variables with a p value below 0.05 were selected.

\section{Impact of exposure variables on the occurrence of diaphragm dysfunction}

To assess the impact of exposure variables on the occurrence of diaphragm dysfunction, forward logistic regression models were built. The dependent variable was the occurrence of diaphragm dysfunction at time of liberation from mechanical ventilation (the day of the first SBT). Due to the number of events in the cohort, the number of exposure variables entering into the model was limited (11). Only the variables with a $\mathrm{p}$ value below 0.05 were selected.

\section{Impact of diaphragm dysfunction and ICU-AW on weaning failure}

The impact of diaphragm and limb muscle strength on subsequent weaning outcome was further assessed. Each potential risk factor for weaning failure was evaluated in a univariate model. Then, four separated forward logistic regressions were performed. Ptr,stim, TFdi, excursion and MRC score, as continuous variables, were each entered into separate multivariate analyses of weaning failure, along with other variables with a $p$ value of $<0.05$ in univariate analysis.

Finally, the associations of diaphragm dysfunction and ICU-AW at inclusion with duration of MV, ICU and hospital length of stay and mortality were further assessed.

\section{Sample size calculation}

After the first 20 patients studied, we observed a prevalence of $60 \%$ of diaphragm dysfunction and $30 \%$ of weaning failure. We reasoned that a sample size of 68 was necessary to allow the identification of an absolute difference of $20 \%$ in the proportion of 
weaning failure in patients with diaphragm dysfunction compared to those without, with a power of $80 \%$ and $\alpha=0.05$. Due to possible loss of follow-up we enrolled $10 \%$ more patients. For all final comparisons, a p-value less than or equal to 0.05 was considered statistically significant. Analyses were performed using SPSS, v.21 (IBM, Chicago, Illinois, USA). 


\section{Results}

Table E1. Impact of exposure variables on the occurrence of diaphragm dysfunction

\begin{tabular}{|c|c|c|c|c|c|c|c|}
\hline \multirow[t]{2}{*}{ Variables } & \multirow[t]{2}{*}{ Event } & \multicolumn{2}{|c|}{ Univariate analysis } & \multicolumn{4}{|c|}{ Multivariate analysis } \\
\hline & & & $\mathrm{P}$ value & B & OR & $95 \% \mathrm{CI}$ & $\mathrm{P}$ value \\
\hline \multirow[t]{2}{*}{ Age, years } & Diaphragm Dysfunction & $61 \pm 13$ & 0.01 & 0.022 & 1.02 & $0.99-1.06$ & 0.24 \\
\hline & No Diaphragm Dysfunction & $51 \pm 18$ & & & & & \\
\hline \multirow[t]{2}{*}{ Coma $^{1}, n(\%)$} & Diaphragm Dysfunction & $7(15)$ & 0.001 & -1.911 & 0.15 & $0.05-0.44$ & 0.001 \\
\hline & No Diaphragm Dysfunction & $15(54)$ & & & & & \\
\hline \multirow[t]{2}{*}{ Days of $\mathrm{MV}^{2}$, days } & Diaphragm dysfunction & $5(2-7)$ & 0.04 & 0.072 & 1.07 & $0.91-1.27$ & 0.41 \\
\hline & No Diaphragm Dysfunction & $3(1-5)$ & & & & & \\
\hline
\end{tabular}

MV, Mechanical ventilation; OR, Odd ratio; CI, Confidence interval, B, Intercept.

${ }^{1}$ Main reason for intubation, ${ }^{2}$ Prior inclusion

Table E2. Impact of exposure variables on the occurrence of ICU-AW

\begin{tabular}{|c|c|c|c|c|c|c|c|}
\hline \multirow[t]{2}{*}{ Variables } & \multirow[t]{2}{*}{ Event } & \multicolumn{2}{|c|}{ Univariate analysis } & \multicolumn{4}{|c|}{ Multivariate analysis } \\
\hline & & & $\mathrm{P}$ value & B & OR & $95 \% \mathrm{CI}$ & $\mathrm{P}$ value \\
\hline \multirow[t]{2}{*}{ Cirrhosis, $n(\%)$} & ICU-AW & $9 / 26$ & 0.01 & 2.104 & 8.20 & $1.82-37.00$ & 0.006 \\
\hline & No ICU-AW & $5 / 50$ & & & & & \\
\hline \multirow[t]{2}{*}{ SOFA score $^{1}$} & ICU-AW & $6 \pm 3$ & 0.04 & 0.008 & 1.01 & $0.82-1.24$ & 0.94 \\
\hline & No ICU-AW & $5 \pm 3$ & & & & & \\
\hline \multirow[t]{2}{*}{ Days of $\mathrm{MV}^{2}$, days } & ICU-AW & $6(4-8)$ & 0.01 & 0.219 & 1.25 & $1.05-1.48$ & 0.01 \\
\hline & No ICU-AW & $3(1-5)$ & & & & & \\
\hline \multirow[t]{2}{*}{ Propofol $^{3}, n(\%)$} & ICU-AW & $9 / 26$ & 0.02 & -0.738 & 0.48 & $0.15-1.50$ & 0.21 \\
\hline & No ICU-AW & $31 / 50$ & & & & & \\
\hline
\end{tabular}

SOFA, Sequential organ failure assessment; MV, Mechanical ventilation; ICU-AW, Intensive care unit - acquired weakness; OR, Odd ratio; CI, Confidence interval, B, Intercept.

${ }^{1}$ On admission, ${ }^{2}$ Prior inclusion, ${ }^{3}$ Exposure prior inclusion. 
Table E3. Impact exposure variables on weaning failure (with Ptr,stim)

\begin{tabular}{|c|c|c|c|c|c|c|c|}
\hline \multirow[t]{2}{*}{ Variables } & \multirow[t]{2}{*}{ Event } & \multicolumn{2}{|c|}{ Univariate analysis } & \multicolumn{4}{|c|}{ Multivariate analysis } \\
\hline & & & $\mathrm{P}$ value & B & OR & $95 \% \mathrm{CI}$ & $P$ value \\
\hline \multirow[t]{2}{*}{ Ptr,stim, $\mathrm{CmH}_{2} \mathrm{O}$} & Weaning Failure & $5.9 \pm 2.7$ & $<0.001$ & -0.511 & 0.60 & $0.45-0.79$ & $<0.001$ \\
\hline & No Weaning Failure & $13.3 \pm 6.2$ & & & & & \\
\hline \multirow[t]{2}{*}{ Age, years } & Weaning Failure & $63 \pm 12$ & 0.01 & -0.015 & 0.99 & $0.94-1.04$ & 0.58 \\
\hline & No Weaning Failure & $54 \pm 17$ & & & & & \\
\hline \multirow[t]{2}{*}{ Days of $\mathrm{MV}^{1}$, days } & Weaning Failure & $6(4-10)$ & $<0.001$ & 0.356 & 1.43 & $1.07-1.90$ & 0.02 \\
\hline & No Weaning Failure & $3(1-5)$ & & & & & \\
\hline \multirow[t]{2}{*}{$\mathrm{Coma}^{2}, n(\%)$} & Weaning Failure & $5(15)$ & 0.02 & -1.014 & 0.36 & $0.06-2.31$ & 0.28 \\
\hline & No Weaning Failure & $17(40)$ & & & & & \\
\hline \multirow[t]{2}{*}{$\mathrm{PaO}_{2} / \mathrm{FiO}_{2}$ ratio ${ }^{1}$} & Weaning Failure & $256(87)$ & 0.01 & 0.001 & 1.00 & $0.99-1.01$ & 0.92 \\
\hline & No Weaning Failure & $322(108)$ & & & & & \\
\hline \multirow[t]{2}{*}{$\mathrm{PaCO}_{2}{ }^{1}, m m H g$} & Weaning Failure & $43 \pm 10$ & 0.02 & 0.052 & 1.05 & $0.95-1.16$ & 0.31 \\
\hline & No Weaning Failure & $37 \pm 7$ & & & & & \\
\hline
\end{tabular}

Ptr,stim, Endotracheal tube pressure induced by bilateral phrenic nerve stimulation during airway occlusion; $\mathrm{MV}$, Mechanical ventilation; $\mathrm{PaO}_{2} / \mathrm{FiO}_{2}$, ratio of arterial oxygen tension to inspired oxygen fraction; $\mathrm{PaCO}_{2}$, Partial carbon dioxide tension; OR, Odd ratio; CI, Confidence interval, B, Intercept.

${ }^{1}$ Prior inclusion, ${ }^{2}$ Main reason for intubation.

Table E4. Impact exposure variables on weaning failure (with TFdi)

\begin{tabular}{|c|c|c|c|c|c|c|c|}
\hline \multirow[t]{2}{*}{ Variables } & \multirow[t]{2}{*}{ Event } & \multicolumn{2}{|c|}{ Univariate analysis } & \multicolumn{4}{|c|}{ Multivariate analysis } \\
\hline & & & $\mathrm{P}$ value & B & OR & $95 \% \mathrm{CI}$ & $P$ value \\
\hline \multirow[t]{2}{*}{ TFdi, $\%$} & Weaning Failure & $19 \pm 9$ & $<0.001$ & -0.177 & 0.84 & $0.76-0.92$ & $<0.001$ \\
\hline & No Weaning Failure & $35 \pm 12$ & & & & & \\
\hline \multirow[t]{2}{*}{ Age, years } & Weaning Failure & $63 \pm 12$ & 0.01 & -0.013 & 1.01 & $0.96-1.07$ & 0.62 \\
\hline & No Weaning Failure & $54 \pm 17$ & & & & & \\
\hline \multirow[t]{2}{*}{ Days of $\mathrm{MV}^{\mathrm{I}}$, days } & Weaning Failure & $6(4-10)$ & $<0.001$ & 0.325 & 1.38 & $1.06-1.81$ & 0.02 \\
\hline & No Weaning Failure & $3(1-5)$ & & & & & \\
\hline \multirow[t]{2}{*}{$\mathrm{Coma}^{2}, n(\%)$} & Weaning Failure & $5(15)$ & 0.02 & -1.268 & 0.28 & $0.05-1.58$ & 0.15 \\
\hline & No Weaning Failure & $17(40)$ & & & & & \\
\hline \multirow[t]{2}{*}{$\mathrm{PaO}_{2} / \mathrm{FiO}_{2}$ ratio ${ }^{1}$} & Weaning Failure & $256(87)$ & 0.01 & -0.002 & 0.99 & $0.99-1.00$ & 0.73 \\
\hline & No Weaning Failure & $322(108)$ & & & & & \\
\hline \multirow[t]{2}{*}{$\mathrm{PaCO}_{2}{ }^{1}, m m H g$} & Weaning Failure & $43 \pm 10$ & 0.02 & 0.034 & 1.04 & $0.95-1.13$ & 0.46 \\
\hline & No Weaning Failure & $37 \pm 7$ & & & & & \\
\hline
\end{tabular}

TFdi, Diaphragm thickening fraction; MV, Mechanical ventilation; $\mathrm{PaO}_{2} / \mathrm{FiO}_{2}$, ratio of arterial oxygen tension to inspired oxygen fraction; $\mathrm{PaCO}_{2}$, Partial carbon dioxide tension; OR, Odd ratio; CI, Confidence interval, B, Intercept.

${ }^{1}$ Prior inclusion, ${ }^{2}$ Main reason for intubation. 
Table E5. Impact exposure variables on weaning failure (with Diaphragm excursion)

\begin{tabular}{|c|c|c|c|c|c|c|c|}
\hline \multirow[t]{2}{*}{ Variables } & \multirow[t]{2}{*}{ Event } & \multicolumn{2}{|c|}{ Univariate analysis } & \multicolumn{4}{|c|}{ Multivariate analysis } \\
\hline & & & $\mathrm{P}$ value & B & OR & $95 \% \mathrm{CI}$ & $\mathrm{P}$ value \\
\hline \multirow[t]{2}{*}{$\mathrm{EXdi}^{\#}, \mathrm{~cm}$} & Weaning Failure & $0.82 \pm 0.42$ & 0.01 & -1.894 & 0.15 & $0.02-0.94$ & 0.04 \\
\hline & No Weaning Failure & $1.12 \pm 0.37$ & & & & & \\
\hline \multirow[t]{2}{*}{ Age, years } & Weaning Failure & $63 \pm 12$ & 0.01 & -0.017 & 0.98 & $0.93-1.04$ & 0.54 \\
\hline & No Weaning Failure & $54 \pm 17$ & & & & & \\
\hline \multirow[t]{2}{*}{ Days of $\mathrm{MV}^{\mathrm{I}}$, days } & Weaning Failure & $6(4-10)$ & $<0.001$ & 0.271 & 1.31 & $1.06-1.61$ & 0.01 \\
\hline & No Weaning Failure & $3(1-5)$ & & & & & \\
\hline \multirow[t]{2}{*}{$\mathrm{Coma}^{2}, n(\%)$} & Weaning Failure & $5(15)$ & 0.02 & -1.81 & 0.16 & $0.03-0.98$ & 0.05 \\
\hline & No Weaning Failure & $17(40)$ & & & & & \\
\hline \multirow[t]{2}{*}{$\mathrm{PaO}_{2} / \mathrm{FiO}_{2}$ ratio ${ }^{1}$} & Weaning Failure & $256(87)$ & 0.01 & -0.001 & 0.99 & $0.99-1.01$ & 0.74 \\
\hline & No Weaning Failure & $322(108)$ & & & & & \\
\hline \multirow[t]{2}{*}{$\mathrm{PaCO}_{2}{ }^{\mathrm{I}}, m m H g$} & Weaning Failure & $43 \pm 10$ & 0.02 & 0.082 & 1.09 & $1.01-1.18$ & 0.04 \\
\hline & No Weaning Failure & $37 \pm 7$ & & & & & \\
\hline
\end{tabular}

EXdi, Excursion of diaphragm; $\mathrm{MV}$, Mechanical ventilation; $\mathrm{PaO}_{2} / \mathrm{FiO}_{2}$, ratio of arterial oxygen tension to inspired oxygen fraction; $\mathrm{PaCO}_{2}$, Partial carbon dioxide tension; $\mathrm{OR}$, Odd ratio; CI, Confidence interval, $\mathrm{B}$, Intercept.

${ }^{1}$ Prior inclusion, ${ }^{2}$ Main reason for intubation.

\# Data available for $58 / 76$ patients.

Table E6. Impact exposure variables on weaning failure (with MRC)

\begin{tabular}{|c|c|c|c|c|c|c|c|}
\hline \multirow[t]{2}{*}{ Variables } & \multirow[t]{2}{*}{ Event } & \multicolumn{2}{|c|}{ Univariate analysis } & \multicolumn{4}{|c|}{ Multivariate analysis } \\
\hline & & & $\mathrm{P}$ value & $\mathrm{B}$ & OR & $95 \% \mathrm{CI}$ & $\mathrm{P}$ value \\
\hline \multirow[t]{2}{*}{ MRC score, point } & Weaning Failure & $43 \pm 14$ & 0.01 & -0.037 & 0.96 & $0.91-1.02$ & 0.20 \\
\hline & No Weaning Failure & $51 \pm 10$ & & & & & \\
\hline \multirow[t]{2}{*}{ Age, years } & Weaning Failure & $63 \pm 12$ & 0.01 & 0.006 & 1.01 & $0.96-1.05$ & 0.79 \\
\hline & No Weaning Failure & $54 \pm 17$ & & & & & \\
\hline \multirow[t]{2}{*}{ Days of $\mathrm{MV}^{1}$, days } & Weaning Failure & $6(4-10)$ & $<0.001$ & 0.283 & 1.33 & $1.10-1.60$ & 0.003 \\
\hline & No Weaning Failure & $3(1-5)$ & & & & & \\
\hline \multirow[t]{2}{*}{$\mathrm{Coma}^{2}, n(\%)$} & Weaning Failure & $5(15)$ & 0.02 & -0.741 & 0.48 & $0.12-1.95$ & 0.30 \\
\hline & No Weaning Failure & $17(40)$ & & & & & \\
\hline \multirow[t]{2}{*}{$\mathrm{PaO}_{2} / \mathrm{FiO}_{2}$ ratio } & Weaning Failure & $256(87)$ & 0.01 & 0.077 & 1.00 & $0.99-1.01$ & 0.42 \\
\hline & No Weaning Failure & $322(108)$ & & & & & \\
\hline \multirow[t]{2}{*}{$\mathrm{PaCO}_{2}, m m H g$} & Weaning Failure & $43 \pm 10$ & 0.02 & 0.079 & 1.08 & $1.01-1.16$ & 0.02 \\
\hline & No Weaning Failure & $37 \pm 7$ & & & & & \\
\hline
\end{tabular}

MRC, Medical research council score; $\mathrm{MV}$, Mechanical ventilation; $\mathrm{PaO}_{2} / \mathrm{FiO}_{2}$, ratio of arterial oxygen tension to inspired oxygen fraction; $\mathrm{PaCO}_{2}$, Partial carbon dioxide tension; OR, Odd ratio; CI, Confidence interval, B, Intercept.

${ }^{1}$ Prior inclusion, ${ }^{2}$ Main reason for intubation. 


\section{References}

1. Boles J-M, Bion J, Connors A, Herridge M, Marsh B, Melot C, Pearl R, Silverman H, Stanchina M, Vieillard-Baron A, Welte T. Weaning from mechanical ventilation. Eur Respir J 2007;29:1033-1056.

2. American Thoracic Society/European Respiratory Society. ATS/ERS Statement on respiratory muscle testing. Am J Respir Crit Care Med 2002;166:518-624.

3. Demoule A, Jung B, Prodanovic H, Molinari N, Chanques G, Coirault C, Matecki S, Duguet A, Similowski T, Jaber S. Diaphragm Dysfunction on Admission to ICU: Prevalence, Risk Factors and Prognostic Impact - a Prospective Study. Am J Respir Crit Care Med 2013; 188:213-9.

4. Mills GH, Ponte J, Hamnegard CH, Kyroussis D, Polkey MI, Moxham J, Green M. Tracheal tube pressure change during magnetic stimulation of the phrenic nerves as an indicator of diaphragm strength on the intensive care unit. Br J Anaesth 2001;87:876884.

5. Supinski GS, Callahan LA. Diaphragm weakness in mechanically ventilated critically ill patients. Crit Care 2013;17:R120.

6. Mills GH, Kyroussis D, Hamnegard CH, Polkey MI, Green M, Moxham J. Bilateral magnetic stimulation of the phrenic nerves from an anterolateral approach. Am J Respir Crit Care Med 1996;154:1099-1105.

7. Watson AC, Hughes PD, Louise Harris M, Hart N, Ware RJ, Wendon J, Green M, Moxham J. Measurement of twitch transdiaphragmatic, esophageal, and endotracheal tube pressure with bilateral anterolateral magnetic phrenic nerve stimulation in patients in the intensive care unit. Crit Care Med 2001;29:1325-1331. 
8. Goligher EC, Laghi F, Detsky ME, Farias P, Murray A, Brace D, Brochard LJ, Sebastien-Bolz S, Rubenfeld GD, Kavanagh BP, Ferguson ND. Measuring diaphragm thickness with ultrasound in mechanically ventilated patients: feasibility, reproducibility and validity. Intensive Care Med 2015;41:642-9

9. Matamis D, Soilemezi E, Tsagourias M, Akoumianaki E, Dimassi S, Boroli F, Richard J-CM, Brochard L. Sonographic evaluation of the diaphragm in critically ill patients. Technique and clinical applications. Intensive Care Med 2013;39:801-810.

10. Levy MM, Dellinger RP, Townsend SR, Linde-Zwirble WT, Marshall JC, Bion J, Schorr C, Artigas A, Ramsay G, Beale R, Parker MM, Gerlach H, Reinhart K, Silva E, Harvey M, Regan S, Angus DC. The Surviving Sepsis Campaign: results of an international guideline-based performance improvement program targeting severe sepsis. Intensive Care Med 2010;36:222-231.

11. Peduzzi P, Concato J, Kemper E, Holford TR, Feinstein AR. A simulation study of the number of events per variable in logistic regression analysis. J Clin Epidemiol $1996 ; 49: 1373-1379$. 